\title{
¿QUÉ FUE DEL RECURSO DE AMPARO ANTE EL TRIBUNAL CONSTITUCIONAL?
}

PEDRO J. TENORIO SÁNCHEZ 
SUMARIO

1. INTRODUCCIÓN. 2. PRIMER PERIODO EN LA INTERPRETACIÓN DE LA REFORMA DE 2007: DE LA PROMULGACIÓN DE LA LEY A LA STEDH ARRIBAS ANTÓN. 3. SEGUNDO PERÍODO EN LA APLICACIÓN DE LA REFORMA DE 2007: DESDE LA STEDH ARRIBAS ANTÓN HASTA LA ACTUALIDAD. 4. BALANCE DE LA APLICACIÓN DE LA REFORMA DE 2007 DIEZ AÑOS DESPUÉS DE SU PROMULGACIÓN. 5. DECEPCIÓN DE LOS JUSTICIABLES. 6. POSIBLES MEJORAS. 


\title{
¿QUÉ FUE DEL RECURSO DE AMPARO ANTE EL TRIBUNAL CONSTITUCIONAL?
}

\author{
PEDRO J. TENORIO SÁNCHEZ ${ }^{1}$ \\ Catedrático de Derecho constitucional. UNED
}

\section{INTRODUCCIÓN}

1. Cuestión que afecta de manera muy relevante a la caracterización de nuestra Justicia Constitucional es la de la configuración del recurso de amparo ante nuestro Tribunal Constitucional y más concretamente la del mantenimiento (y perfeccionamiento) o supresión del requisito de la especial trascendencia constitucional para la admisión del mencionado recurso.

Los antecedentes de la cuestión en el ámbito legislativo, el debate doctrinal en torno a las referidas reformas legislativas, y en particular acerca de la reforma de la LOTC de $2007^{2}$, así como el balance de la aplicación de la referida reforma en algunos años sucesivos han sido ya tratados doctrinalmente ${ }^{3}$.

2. Los principales propósitos de la LO 6/2007, de 24 de mayo, fueron, según proclamó la propia Exposición de motivos del Proyecto de ley, resolver el colapso del Tribunal Constitucional y reforzar la posición institucional del mismo.

Las dos novedades más relevantes que incorporó la reforma, en cuanto al asunto que nos ocupa ${ }^{4}$, fueron: a) el trámite de admisión al recurso de amparo, con la introducción del requisito de la «especial trascendencia constitucional», y b) la reforma

${ }^{1}$ Catedrático de Derecho Constitucional. Facultad de Derecho. Universidad Nacional de Educación a Distancia. Calle Obispo Trejo, 2.28040 Madrid. Email: ptenorio@der.uned.es

2 Ley orgánica 6/2007, de 24 de mayo.

3 V. al respecto Torres del Moral, A., Principios de Derecho Constitucional español, Tomo I. Sistema de fuentes. Sistema de los derechos, 6. ${ }^{a}$ edición, Servicio Publicaciones Facultad de Derecho Universidad Complutense, Madrid, 2010, pp. 695 y ss.Y la bibliografía allí citada.

4 Acerca de la reforma en el ámbito del control de constitucionalidad de la ley, v. Hernández CorCHete, J. A.., «La función de control de constitucionalidad de la ley en materia no competencial», en $L a$ defensa de los derechos fundamentales: Tribunal Constitucional y Poder Judicial, CEPC 2010, pp. 213 ss. 
del incidente de nulidad de actuaciones como recurso previo a la interposición del de amparo 5 .

La gran novedad fue la reforma del régimen de admisión del recurso de amparo. En el régimen anterior a la reforma, los recursos de amparo debían admitirse salvo que concurriera alguna de las causas de inadmisión previstas en la ley ${ }^{6}$. La reforma invirtió esta orientación al prever que los recursos de amparo sólo se admitirían cuando concurrieran determinados requisitos y siempre y cuando así lo acordaran por unanimidad los Magistrados de la Sección correspondiente. Si sólo se obtuviera mayoría, sería preciso que decidiera la Sala.

Los requisitos para la admisión según el vigente art. 50 LOTC son pues, por un lado, que se cumplan determinadas exigencias formales contempladas en los arts. 41 a 46 y 49 y, por otro, que el contenido del recurso justifique una decisión sobre el fondo por parte del Tribunal Constitucional en razón de su «especial trascendencia constitucional», que se apreciará atendiendo a su importancia para la interpretación de la Constitución, para su aplicación o para su general eficacia, y para la determinación del contenido y alcance de los derechos fundamentales.

3. Transcurridos diez años desde la reforma de la LOTC de 2007, el debate respecto de la configuración del recurso de amparo y en particular sobre el requisito de la «especial transcendencia constitucional», sigue abierto. Parece que sobre todo ha generado frustración y decepción entre justiciables y abogados, aunque también se critica en el ámbito académico.

Esto nos obliga a hacer balance de los resultados que ofrece la reforma de 2007 en su conjunto. ¿Ha conseguido el principal objetivo perseguido, que era acabar con la congestión del Tribunal Constitucional? ${ }^{7}$

4. Por otra parte, estudiar la actualidad del recurso de amparo ante el Tribunal Constitucional es sobre todo analizar la interpretación y aplicación de la reforma de la LOTC de 2007. Para ello, contamos no solamente con la jurisprudencia del Tribunal Constitucional, sino con las Memorias que publica en su página web el mismo.

5 V. Bachmaier Winter, L., «La reforma del recurso de amparo en la Ley Orgánica 6/2007, de 24 de mayo», La Ley, 10 de septiembre 2007 (n. ${ }^{\circ}$ 6775), pp. 1-5; así como «La reforma de la Ley Orgánica del Tribunal Constitucional y la nulidad de actuaciones», Nueva Revista General de Derecho Procesal, Iustel (ISSN 1696-9642), núm. 13, octubre 2007 (http://www.iustel.com) y Revista Derecho Procesal, (ISSN 0213-1137), 2007/1-3, pp. 45-67.

6 Antiguo art. 50 LOTC (inmediatamente anterior a la reforma).

7 Algunos autores han cuestionado no solamente la utilidad de la introducción del requisito de la «especial trascendencia constitucional» para lograr el descenso del número de recursos de amparo, sino que han formulado objeciones de constitucionalidad. En este sentido, se ha señalado que la introducción de este requisito supone que el legislador impone al Tribunal Constitucional, supremo intérprete de la Constitución, unos criterios de interpretación sobre el alcance de la infracción de los derechos fundamentales que, en principio, compete juzgar en exclusiva al propio Tribunal. V. Alegre Ávila, J. M., «El amparo constitucional: un asunto de ¿nunca acabar?» REDA, núm. 138, 2008, p. 202. 
Con base en ellas, hemos elaborado un cuadro, el número 1 del presente trabajo, en el que recogemos la evolución de determinados datos desde 2002 a 2016. Nos remontamos tanto porque lo consideramos necesario para recordar la situación en que se encontraba el Tribunal antes de la reforma de 2007, situación en la que se avecinaba el colapso del mismo. En efecto, puede comprobarse que en el año 2006 se interpusieron 11471 recursos de amparo, la cifra de recursos de amparo pendientes de resolución sobre la admisibilidad era de 13883 y subía de manera alarmante en los años anteriores. Al mismo tiempo, había 622 sentencias por dictar por parte del Pleno y este último dictaba entonces solamente entre 22 y 63 sentencias al año.

\begin{tabular}{ccccccc}
\multicolumn{7}{c}{ Cuadro número $1^{8}$} \\
\hline Años & $\begin{array}{c}\text { Recursos de } \\
\text { amparo } \\
\text { interpuestos }\end{array}$ & $\begin{array}{c}\text { Recursos de } \\
\text { amparo } \\
\text { pendientes } \\
\text { de admisión }\end{array}$ & $\begin{array}{c}\text { Sentencias } \\
\text { de amparo } \\
\text { pendientes }\end{array}$ & $\begin{array}{c}\text { Recursos de } \\
\text { amparo } \\
\text { resueltos por } \\
\text { sentencia }\end{array}$ & $\begin{array}{c}\text { Sentencias } \\
\text { de Pleno } \\
\text { dictadas }\end{array}$ & $\begin{array}{c}\text { Asuntos de } \\
\text { Pleno } \\
\text { pendientes } \\
\text { de sentencia }\end{array}$ \\
\hline 2002 & 7285 & 6040 & 353 & 221 & 22 & 510 \\
2003 & 7721 & 7071 & 413 & 207 & 28 & 507 \\
2004 & 7814 & 7580 & 498 & 195 & 63 & 511 \\
2005 & 9476 & 10990 & $403 *$ & 303 & 42 & 482 \\
2006 & 11471 & 13883 & 270 & 327 & 41 & 622 \\
2007 & 9480 & 12166 & 313 & 231 & 35 & 585 \\
2008 & 10279 & 9015 & 305 & 165 & 22 & 524 \\
2009 & 10792 & $4569 *$ & 173 & 177 & 20 & 411 \\
2010 & 8948 & 3149 & 203 & 91 & 48 & 407 \\
2011 & 7098 & 3420 & 145 & 145 & 59 & 284 \\
2012 & 7205 & 2895 & 142 & 124 & 136 & 302 \\
2013 & 7376 & 3738 & 167 & 87 & 129 & 259 \\
2014 & 7663 & 4463 & 116 & 109 & 95 & 256 \\
2015 & 7203 & 3312 & 99 & 96 & 107 & 223 \\
2016 & 6685 & 2358 & 74 & 88 & 125 & 160 \\
\hline
\end{tabular}

Huelga decir que hay escrupulosa continuidad en la jurisprudencia de nuestro Tribunal Constitucional relativa a la aplicación de la reforma de 2007. Pero esta coherencia de fondo no obsta a intentar señalar alguna evolución en la misma. Los cambios no han sido abruptos, sino paulatinos, si bien se pueden señalar algunos hitos. Seguramente el más significativo fue el que supuso la STC 155/2009, de 25 de

${ }^{8}$ El cuadro es de elaboración propia, pero realizado con los datos que proporcionan las Memorias del Tribunal Constitucional. En particular, se han consultado sobre todo las memorias correspondientes a los años 2016, 2013, 2009 y 2006. Estas Memorias proporcionan cuadros comparativos de los últimos años por lo que no ha sido necesario consultar cada uno de los años. Solamente se han encontrado algunas diferencias en dos datos que hemos señalado con asterisco, pero no resultan particularmente significativas las discrepancias. 
junio, que en el FJ 2 enumeró y sistematizó los criterios para fundamentar la «especial transcendencia constitucional» de los recursos de amparo.

Sin embargo, quizás se puede señalar que el Tribunal aplicó al principio con algunas reservas el espíritu de la reforma de la LOTC de 2007, para ir ejecutándola posteriormente cada vez con más determinación. En este proceso influyó, seguramente de forma no querida, la STEDH de 20 de enero de 2015, caso Arribas Antón v. España, n. ${ }^{\circ}$ 16563/11. De manera que, a efectos meramente expositivos, sin que con ello pretendamos decir que tal Sentencia provocó un vuelco en la jurisprudencia de nuestro Tribunal Constitucional, vamos a distinguir dos periodos en el desenvolvimiento de la aplicación por parte de nuestro Alto Tribunal de la reforma de 2007 de su ley reguladora.

Una vez descritos los criterios implantados por nuestro Tribunal Constitucional a lo largo de estos dos periodos, dedicaremos un espacio a realizar un balance o valoración de conjunto de la aplicación de la reforma de 2007 por parte de nuestro Tribunal Constitucional.

Haremos algunas observaciones acerca de uno de los efectos que, en nuestra opinión, ha tenido la reforma de 2007: la decepción de los justiciables.

Concluiremos haciendo algunas sugerencias que tal vez podrían mejorar la situación.

\section{PRIMER PERIODO EN LA INTERPRETACIÓN DE LA REFORMA DE 2007: DE LA PROMULGACIÓN DE LA LEY A LA STEDH ARRIBAS ANTÓN}

1. El Tribunal Constitucional pronto distinguió entre vulneración del derecho fundamental y especial trascendencia constitucional, exigiendo la concurrencia de ambos requisitos para la admisión.

El propio Alto Tribunal entendió que se había producido una objetivación del amparo en la STC 155/2009, de 25 de junio, FJ 2, si bien precisó que la lesión sigue siendo requisito del amparo, diciendo literalmente que «tras la reforma llevada a cabo la mera lesión de un derecho fundamental o libertad pública tutelable en amparo ya no será por sí sola suficiente para admitir el recurso [...].»

Desde el primer momento, el Guardián de la Constitución afirmó que la «especial trascendencia constitucional» era distinta de la existencia de lesión. Hubo un momento en que el Tribunal incluyó, en algunas de sus resoluciones, cualquier inadmisión por motivos de fondo, es decir, lo que antes se llamaba inadmisión por «falta de contenido constitucional que justifique una resolución sobre el fondo»? ${ }^{9}$. Pero con posterioridad el Tribunal consideraría que la inexistencia de lesión se reconduce al art. 50.1.a LOTC, mientras que la falta de «especial trascendencia constitucional»se reconduce al art. 50.1.b LOTC.

9 AATC 272/2009, de 26 noviembre, FJ 1 y 274/2009, de 30 noviembre, FJ 3. 
2. El Tribunal Constitucional colaboró decisivamente en la interpretación de los supuestos de especial trascendencia constitucional no solo con la STC 155/2009, sino con ulterior interpretación de los motivos sistematizados en la misma.

El supremo Tribunal consideraba que no era necesario explicitar en sus resoluciones el motivo concurrente de especial transcendencia constitucional, por lo que solo lo reflejaba en casos excepcionales. Por ello, en un primer momento, el Tribunal precisó más bien, supuestos en que no concurría especial transcendencia constitucional. Así, el Tribunal no considerará de especial trascendencia constitucional el hecho de que el recurso de amparo revista importancia para el interés público ${ }^{10}$, ni el hecho de que tenga importancia para el correcto funcionamiento de la Administración Pública $^{11}$, o que la decisión del recurso permita salvaguardar los intereses generales de las entidades locales o la tutela judicial efectiva de los mismos ${ }^{12}$.

La distinción entre vulneración del derecho fundamental y especial trascendencia constitucional le llevará a precisar que no constituye especial transcendencia constitucional el hecho de que la resolución impugnada haya supuesto una vulneración notoria del derecho fundamental ${ }^{13}$.

Un punto que quizás esté necesitado de precisión es la determinación de si cada queja que se exponga ante el Tribunal Constitucional debe suponer la alegación tanto de una vulneración de un derecho fundamental, como la de un motivo de especial transcendencia constitucional. En efecto, por una parte el Tribunal ha afirmado que aun cuando la razón de especial trascendencia constitucional es diferente de la lesión aducida, debe haber conexión entre ambas; en caso contrario, no se considera que concurre «especial trascendencia constitucional» ${ }^{14}$. Hay doctrina constitucional sin embargo según la cual no se exige que la justificación de la especial trascendencia constitucional se refiera a todos los motivos o quejas del recurso. En este sentido se pronunció la STC 2/2013, de 14 de enero, FJ 3, sentando una doctrina luego confirmada, entre otras, por la STC 203/2015, de 5 de octubre, FJ 2. Hasta donde hemos alcanzado a ver, nuestro Alto Tribunal no ha precisado qué ocurre cuando la especial trascendencia constitucional que aduce el recurrente solo tiene conexión con un motivo del recurso que parezca no tener contenido constitucional en el trámite de admisión o que no lo tenga al dictar sentencia. En nuestra opinión, como la especial trascendencia constitucional es requisito que se valora en el trámite de admisión, si el recurso es admitido, no procederá desestimar o inadmitir el motivo en sentencia porque se considere, al dictar la misma, que no concurre el requisito introducido en la reforma de 2007.

El Tribunal considera que no concurre el requisito de la «especial trascendencia constitucional» si ya existe doctrina sobre la materia y cuestión planteados. En este

10 ATC 61/2010, de 31 de mayo, FFJJ 1 y 2.

11 ATC 61/2010, de 31 de mayo, FFJJ 1 y 2

12 ATC 173/2010, de 17 de noviembre, Antecedentes 3 y 4 y FJ 3

13 ATC 201/2010, de 21 de diciembre, Antecedente 5 y FFJJ 1 y 2

${ }_{14}$ ATC 98/2015, de 1 de junio, FFJJ 1 y 3 
sentido, el Tribunal descarta que sea de «especial transcendencia constitucional» fijar doctrina acerca de la inmediación y la oralidad en la segunda instancia penal ${ }^{15}$; o acerca del derecho de participación política de los concejales no adscritos a un grupo municipal ${ }^{16}$. En cuanto a la concurrencia de especial trascendencia constitucional por incumplimiento general y reiterado de doctrina constitucional, el Tribunal ha hecho dos precisiones de interés. Por una parte, ha señalado que no es suficiente con que se acredite un número de sentencias estimatorias de amparo por la misma lesión, sino que además debe evidenciarse que la práctica judicial posterior a la formulación de esa doctrina no ha procurado adecuarse a ésta ${ }^{17}$.

Por otra parte, el Tribunal ha señalado, ya en el periodo anterior a la STEDH Arribas Antón, que para apreciar que existe especial trascendencia constitucional no es necesario que concurra negativa manifiesta al acatamiento de la doctrina constitucional (AATC 26/2012, de 31 de enero, FJ 3 y 141/2012, de 9 de julio, FJ Único). En este punto veremos matizaciones posteriores.

3. El Tribunal Constitucional, ya desde este periodo, estableció las bases para distinguir la existencia, como presupuestos de admisibilidad diferenciados, de la especial trascendencia constitucional y la justificación de esta última, pues no basta que un asunto presente especial trascendencia constitucional, sino que la ley impone al recurrente la carga de justificarla.

Es doctrina del Tribunal que el «momento procesal idóneo» para el análisis del cumplimiento de la «especial trascendencia constitucional» es el trámite de admisión de la demanda de amparo ${ }^{18}$; por el contrario, la falta de justificación de «especial trascendencia constitucional» puede ser apreciada en la sentencia aunque se debe hacer un uso prudente de esta facultad de inadmitir posteriormente a la demanda, de la misma manera que ocurre con otros defectos como la falta de claridad ${ }^{19}$. Esta distinción ha exigido al Tribunal construir una doctrina sobre el tratamiento del requisito de la justificación de la especial transcendencia constitucional, afirmando que es requisito sustancial e insubsanable, así como acerca del control del Tribunal sobre su concurrencia efectiva en el caso concreto ${ }^{20}$.

Por supuesto, el Tribunal considera que no se cumple con el requisito de la justificación de la especial trascendencia constitucional en todos aquellos casos en que no se menciona este requisito en la demanda ${ }^{21}$. Si la demanda afirma que se da cum-

\footnotetext{
15 ATC 44/2015, de 25 de febrero, FJ 2

${ }_{16}$ AATC 46/2011, de 28 de abril, FFJJ 3 y 4 y 67/2011, de 6 de junio, FJ Único, entre otros

${ }_{17}$ ATC 44/2015, de 25 de febrero, FJ 2

${ }^{18}$ STC $126 / 2013$, de 13 de junio, FJ 2.C.

19 STC 212/2013, de 16 de diciembre, FJ 2.

${ }^{20}$ Esta doctrina la encontramos en la STC 118/2014, de 8 de julio, FJ 2.c), después confirmada por otras, como la STC 160/2015, de 14 de julio, FJ 2.

${ }^{21}$ En este sentido, son de mencionar entre otros, los AATC: 188/2008, de 21 de julio, FJ 4; 4/2016, de 18 de enero, FJ único. También se pueden señalar sentencias, como las SSTC 143/2011, de 26 de septiembre, FJ 2 y 160/2015, de 14 de julio, FJ 3.
} 
plimiento a la carga de justificar la «especial trascendencia constitucional» pero, leída la misma, se constata que no hay argumentación en tal sentido, el requisito, obviamente, no queda cumplido ${ }^{22}$. Tampoco se ha justificado la «especial trascendencia constitucional» en aquellos casos en que el recurso, sin argumentar, sostiene que es evidente la trascendencia constitucional del recurso ${ }^{23}$.

En algún caso el Tribunal ha admitido que la justificación de la «especial trascendencia constitucional» se haga en un escrito de ampliación de la demanda que supla la omisión de la misma, pero dicho escrito de ampliación ha de presentarse dentro del tiempo del plazo legal de interposición del recurso de amparo ${ }^{24}$.

Nuestro Tribunal Constitucional ha formulado doctrina que exige que la justificación de la «especial transcendencia constitucional» sea suficiente ${ }^{25}$. Doctrina que tiene una formulación general pero también especificaciones posteriores, en alguna de las cuales la justificación insuficiente resulta difícil de distinguir, en nuestra opinión, de la falta de justificación. Esta posición consiste en sostener que determinadas formas de argumentación no son suficientes. En este sentido, nuestro Tribunal ha señalado la insuficiencia de argumentar sobre la lesión de fondo ${ }^{26}$, como también que la mera existencia de un apartado en la demanda titulado «justificación de la especial trascendencia constitucional» no es suficiente si su contenido efectivo es argumentar sobre la denuncia de la lesión de fondo ${ }^{27}$, o cuando la demanda de amparo emplea expresiones similares, pero analizada en cuanto al fondo, se contrae a argumentar en torno a la propia vulneración del derecho fundamental ${ }^{28}$.

Tampoco es aceptable argumentar que la «especial trascendencia constitucional» se deduce de la mera lectura de los hechos que produjeron la lesión ${ }^{29}$ o aducir la trascendencia constitucional evidente de los derechos invocados ${ }^{30}$; ni afirmar únicamente el evidente contenido constitucional del recurso ${ }^{31}$; o citar todos o alguno de los incisos del art. 50.1 b) LOTC, pero sin añadir argumentación alguna que permita concluir su concurrencia en el caso concreto ${ }^{32}$; o referirse a todos o alguno de los supuestos enumerados en la STC 155/2009, FJ 2, pero sin añadir argumen-

22 Esto ocurrió en el supuesto del ATC 165/2009, de 25 de mayo, FJ único.

23 Es el caso del ATC 252/2009, de 19 de octubre, FJ 2.

${ }_{24}$ En este sentido, AATC 262/2009, de 11 de noviembre, FJ 2 y 24/2012, de 31 de enero, FJ 1.

25 Esta doctrina se formula en la STC 118/2014, de 8 de julio, FJ 2.c) y se confirma en otras posteriores, como la STC 160/2015, de 14 de julio, FJ 2.

${ }^{26}$ En este sentido, encontramos los AATC 154/2010, de 15 de noviembre, FJ 4 o 31/2015, de 16 de febrero, FJ 2.

27 Esta doctrina la encontramos en los AATC 80/2009, de 9 de marzo, FJ 2 o 87/2015, de 18 de mayo, Antecedente 2.a) y FJ Único. También en la STC 140/2013, de 8 de julio, FJ 5.

${ }_{28}$ En este sentido, AATC 236/2009, de 7 de septiembre, FJ 1 y FJ 2, o 11/2012, de 26 de enero, FJ 3, entre otros.

29 STC 178/2012, de 15 de octubre, FJ 4

30 AATC 48/2011, de 5 de mayo, Antecedente 3 y FJ 2

31 ATC 25/2013, de 6 de febrero, FJ 4

32 ATC 187/2010, de 29 de noviembre, FJ Único; STC 69/2011, de 16 de mayo, FJ 4 
tación que permita concluir la concurrencia de alguno de los supuestos en el caso concreto $^{33}$; o solicitar del Tribunal Constitucional que revise una interpretación judicial de la Ley que se considera lesiva de los derechos fundamentales que, contradictoriamente, se invoca ${ }^{34}$.

Otro conjunto de supuestos en que el Tribunal Constitucional considera que no se cumple con el requisito de la justificación de la «especial trascendencia constitucional» está constituido por los supuestos en que la argumentación gira en torno al fin de reparación de los derechos vulnerados, pero sin intención de objetivar el recurso. En este sentido, se considera que no se cumple el requisito cuando la demanda de amparo justifica la especial trascendencia constitucional sobre la base de la situación particular del recurrente ${ }^{35}$; o sobre la base de la gravedad de la lesión ${ }^{36}$.

Hay resoluciones que rechazan la justificación de la «especial trascendencia constitucional»sobre la base de la argumentación que la relaciona con la defensa de la doctrina constitucional. En este sentido, el Tribunal no considera suficiente argumentar que la resolución impugnada contradice una determinada doctrina ${ }^{37}$; tampoco es suficiente argumentar sobre la base de que el Tribunal Constitucional, mediante la estimación del recurso, mantenga la interpretación ya efectuada sobre un derecho fundamental ${ }^{38}$.

En fin, también ha rechazado el Tribunal Constitucional que se pueda considerar justificada la «especial trascendencia constitucional» si se aduce contradicción con la jurisprudencia del Tribunal Supremo o de Audiencias Provinciales; o por el hecho de que la resolución contra la que se recurre haya sido dictada por el Tribunal Supremo ${ }^{39}$.

4. Las dudas acerca de la constitucionalidad del requisito de la «especial trascendencia constitucional» quedaron en buena medida disipadas cuando el TEDH consideró que la introducción del mismo no era contraria al Convenio Europeo de Derechos Humanos. En efecto, se planteó ante el TEDH la posible vulneración del art. $6 \mathrm{CEDH}$ por la inadmisión mediante providencia que simplemente aludía a la falta de «especial trascendencia constitucional», pero el referido Tribunal, en Decisión de 25 de septiembre de 2012, asunto Pedro María Beraza Oroquieta, C. España no consideró que existiera vulneración del $\mathrm{CEDH}$. Pero posteriormente, como veremos, habrá otro pronunciamiento del TEDH más concluyente.

\footnotetext{
33 AATC 134/2010, de 4 de octubre, FJ 2; 26/2012, de 31 de enero, FJ 3

4 ATC 236/2009, de 7 de septiembre, FFJJ 1 y 2

5 ATC 240/2009, de 21 de septiembre, FFJJ 1 y 2

6 ATC 29/2011, de 17 de marzo, FJ 3

37 AATC 96/2010, de 19 de julio, Antecedente 3 y FJ Único; y ATC 87/2015, de 18 de mayo, Antecedente 2.a) y FJ Único

38 ATC 187/2010, de 29 de noviembre, FJ Único; ATC 42/2012, de 7 de marzo, FJ 3

39 ATC 154/2010, de 15 de noviembre, FJ 4
} 
5. Se ha considerado por algunos que la valoración de si un asunto tiene o no «especial transcendencia constitucional» es decisión discrecional del Tribunal Constitucional. En nuestra opinión, tal planteamiento resulta difícilmente conciliable con el principio de imperio de la ley y la naturaleza jurisdiccional de la función del Alto Tribunal. Ahora bien, tal vez impulsos en principio contradictorios han contribuido a que el Tribunal Constitucional, sin emplear el término «discrecional», al menos en cuanto hemos alcanzado a ver, se ha situado en algún sentido en esta línea. Decimos que a ello han contribuido impulsos contradictorios porque esta concepción convenía tanto a los que contemplaron la reforma de 2007 como la introducción de un certiorari puro, como a los que consideraron que la introducción de la especial transcendencia constitucional como requisito de admisión era poco garantista, pues estos últimos han podido ver en aquella discrecionalidad la posibilidad de admitir casos que no cumplían en algún sentido con el requisito de la «especial transcendencia constitucional» pero en los que la vulneración del derecho fundamental fuera particularmente clara o grave.

Decimos que nuestro Tribunal Constitucional se orienta en el sentido de la discrecionalidad en la medida en que afirma que solo a él le corresponde decidir si concurre o no la «especial trascendencia constitucional» en un asunto. Varias de sus Sentencias han reiterado esta cuestión en tales términos que el Ministerio Fiscal considera que no es posible recurrir las providencias de inadmisión en las que el Tribunal afirma que no concurre el requisito de la «especial trascendencia constitucional» (a diferencia de lo que ocurre con las providencias en las que se afirma que no ha habido justificación de la «especial trascendencia constitucional» $)^{40}$.

Entendemos que con el sistema de la «especial trascendencia constitucional» la potestad de admisión es una potestad reglada, aunque sea mediante conceptos jurídicos indeterminados o abiertos ${ }^{41}$. A pesar del establecimiento del requisito de la «especial trascendencia constitucional», de difícil control, la admisión sigue siendo reglada. Además, de alguna manera, el propio Tribunal Constitucional, al formular los criterios de la STC 155/2009, se sitúa en esta línea.

6. Consideramos que durante este periodo no se aplicó plenamente el espíritu de la reforma de 2007.

La reforma, en los primeros años, fracasó parcialmente, quizás porque no se aplicó hasta sus últimas consecuencias. El propio Tribunal no parecía considerar suficien-

${ }^{40}$ En este sentido, SSTC 54/2015, de 16 de marzo, FJ 4; 89/2016, de 9 de mayo, FJ 2 o 172/2016, de 17 de octubre, así como las sentencias citadas en las mismas.

${ }^{41}$ En este sentido, Fernández SEgado, F., La reforma del régimen jurídico procesal del recurso de amparo, 2008, pp. 130 y 131; también Montañés PARDO, M. Á., «La "especial trascendencia constitucional” como presupuesto del recurso de amparo», Revista OTROSÍ, núm. 1, enero de 2010, p. 32 y Cabañas García, J. C., «El recurso de amparo que queremos (Reflexiones a propósito de la Ley Orgánica 6/2007, de 24 mayo, de reforma parcial de la Ley Orgánica del Tribunal Constitucional)», en Revista Española de Derecho Constitucional, número 88, enero-abril (2010), p. 74. 
te la compensación que se ofrecía a los justiciables ampliando el incidente de nulidad de actuaciones e intentó recuperar la subjetivación del amparo, paradójicamente, resaltando su propia discrecionalidad frente a lo que parece la voluntad de la ley.

Si se pretendía habilitar al Tribunal Constitucional para que dictara sentencia en los diez o doce asuntos de amparo más importantes de cada año, la reforma, a la altura de 2012, no lo había conseguido. Y no es que hubiera 110 asuntos de especial trascendencia constitucional al año que se plantearan ante nuestro Tribunal Constitucional. Prueba de ello es que todavía en 2013 se podían encontrar sentencias ${ }^{42}$ en que se falla que el recurrente no justificó la «especial trascendencia constitucional». Se inadmitió en Sentencia porque no se había justificado la «especial trascendencia constitucional», no porque el asunto no la tuviera. Se trata de asuntos, por tanto, que no debían de haber superado el trámite de admisión.

Esto tiene su explicación. En efecto, en la jurisprudencia del Tribunal posterior a 2007 asistimos a una atemperación de la objetivación legal del recurso de amparo. Ciertamente, en los autos que se dictaron en $2008^{43}$ el Tribunal fue tajante en exigir que el recurrente adujera razones de «especial trascendencia constitucional», considerando la argumentación correspondiente como un requisito sine qua non del recurso de amparo, que además tendría carácter insubsanable.

Pero un año después tan solo ${ }^{44}$, en la STC 155/2009, de 25 de junio, FJ 2, en la que el Tribunal, en una Sentencia de Pleno precisa el concepto de trascendencia constitucional, se abre a sí mismo las puertas para poder admitir aquellos recursos en los que exista vulneración constitucional y un perjuicio grave para el recurrente, aunque sea reconduciendo estos supuestos a un concepto amplio de «especial trascendencia constitucional» ${ }^{45}$.

${ }^{42}$ STC $140 / 2013$, de 8 de julio de 2013.

43 AATC 188/2008, de 21 de julio, FJ 1; 289/2008 y 290/2008, de 22 de septiembre, FJ 2.

44 Requejo Pagés ya señaló el cambio en los AATC 272 y 274/2009 (REQUEjo PAGÉs, J.L., «Doctrina del Tribunal Constitucional durante el tercer cuatrimestre de 2009», REDA, n. 88, pp. 312 y ss.).

45 Reproducimos el fragmento: «... cabe apreciar que el contenido del recurso de amparo justifica una decisión sobre el fondo en razón de su especial trascendencia constitucional en los casos que a continuación se refieren, sin que la relación que se efectúa pueda ser entendida como un elenco definitivamente cerrado de casos en los que un recurso de amparo tiene especial trascendencia constitucional, pues a tal entendimiento se opone, lógicamente, el carácter dinámico del ejercicio de nuestra jurisdicción, en cuyo desempeño no puede descartarse a partir de la casuística que se presente la necesidad de perfilar o depurar conceptos, redefinir supuestos contemplados, añadir otros nuevos o excluir alguno inicialmente incluido.

Tales casos serán los siguientes: a) el de un recurso que plantee un problema o una faceta de un derecho fundamental susceptible de amparo sobre el que no haya doctrina del Tribunal Constitucional, supuesto ya enunciado en la STC 70/2009, de 23 de marzo; b) o que dé ocasión al Tribunal Constitucional para aclarar o cambiar su doctrina, como consecuencia de un proceso de reflexión interna, como acontece en el caso que ahora nos ocupa, o por el surgimiento de nuevas realidades sociales o de cambios normativos relevantes para la configuración del contenido del derecho fundamental, o de un cambio en la doctrina de los órganos de garantía encargados de la interpretación de los tratados y acuerdos internacionales a los que se refiere el art. 10.2 CE; c) o cuando la vulneración del derecho fundamental que se denuncia provenga de la ley o de otra disposición de carácter general; d) o si la vulneración del derecho fundamental traiga causa de una reiterada interpretación jurisprudencial de la ley que el Tribunal Constitucional considere lesiva del derecho fundamental y crea necesario proclamar otra 
En este sentido puede interpretarse ${ }^{46}$ el último de los supuestos de trascendencia constitucional que enumera la STC $155 / 2009^{47}$, el que podríamos denominar cláusula de apertura, más que de cierre, a la ejemplificación que hace la Sentencia de los supuestos de «especial trascendencia constitucional». La voluntad del Tribunal no es la de cerrar el concepto de «especial transcendencia constitucional» y circunscribirlo al menor número de supuestos posibles, como se percibe también en la introducción que hace el Tribunal a la enumeración de los supuestos de trascendencia constitucional.

Es cierto que el Tribunal no lo dice expresamente, es verdad que no dice que en aquellos supuestos en los que exista vulneración constitucional y perjuicio grave para el recurrente cabe la admisión en virtud del concepto de trascendencia constitucional; pero también lo es que se autoconcede una discrecionalidad tan amplia que le permite dictar sentencias sobre este tipo de supuestos, acaso desvirtuando el requisito de la «especial trascendencia constitucional» como concepto indeterminado, pero determinable, que mantiene el carácter reglado de la admisión.

A la altura de 2012, bastaba repasar el número de sentencias sobre recursos de amparo que se dictan al año para comprobar que el Tribunal no estaba siguiendo lo que fue la inspiración de la reforma. En efecto, una de las inspiraciones de la reforma fue el ejemplo del Tribunal Supremo de Estados Unidos. Allí, cada año llegan al Tribunal Supremo más de 9.000 peticiones de revisión y cada año, al menos en los últimos tiempos, se aceptan para revisión menos de $80 \operatorname{casos}^{48}$. Nues-

\footnotetext{
interpretación conforme a la Constitución; e) o bien cuando la doctrina del Tribunal Constitucional sobre el derecho fundamental que se alega en el recurso esté siendo incumplida de modo general y reiterado por la jurisdicción ordinaria, o existan resoluciones judiciales contradictorias sobre el derecho fundamental, ya sea interpretando de manera distinta la doctrina constitucional, ya sea aplicándola en unos casos y desconociéndola en otros; f) o en el caso de que un órgano judicial incurra en una negativa manifiesta del deber de acatamiento de la doctrina del Tribunal Constitucional (art. 5 de la Ley Orgánica del Poder Judicial: LOPJ); g) o, en fin, cuando el asunto suscitado, sin estar incluido en ninguno de los supuestos anteriores, trascienda del caso concreto porque plantee una cuestión jurídica de relevante y general repercusión social o económica o tenga unas consecuencias políticas generales, consecuencias que podrían concurrir, sobre todo, aunque no exclusivamente, en determinados amparos electorales o parlamentarios.» (FJ 2).

46 Es discutible que se trate de una auténtica cláusula de cierre que no permita discrecionalidad. Para analizar la cuestión, sería necesaria una cuidadosa lectura de toda la STC 155/2009 que excede del objeto de este trabajo.

47 «Cuando el asunto suscitado, sin estar incluido en ninguno de los supuestos anteriores, trascienda del caso concreto porque plantee una cuestión jurídica de relevante y general repercusión social o económica o tenga unas consecuencias políticas generales, consecuencias que podrían concurrir, sobre todo, aunque no exclusivamente, en determinados amparos electorales o parlamentarios.»

48 Ahumada Ruiz, M. Á., «Certiorari y criterios de selección de casos en la última instancia: qué casos, cuántos casos», en La defensa de los derechos fundamentales: Tribunal Constitucional y Poder Judicial. Actas de las XV jornadas de la Asociación de Letrados del Tribunal Constitucional, Tribunal Constitucional - Centro de Estudios Políticos y Constitucionales, Madrid, 2010, pp. 59 y ss., especialmente p. 78.
} 
tro Tribunal Constitucional no había conseguido reconducir el amparo a unos límites parecidos ${ }^{49}$.

Conste que decimos que el Tribunal no había aplicado el espíritu de la reforma, no que no hubiera aplicado la reforma. Porque el modelo de Estados Unidos, en nuestra opinión, fue solamente una fuente de inspiración de la reforma, pero no es el modelo que queda plasmado en la misma. Efectivamente, en el modelo estadounidense la denegación de la petición de revisión de un asunto solo significa que no hubo cuatro jueces que, por pura discreción, consideraron conveniente revisar la decisión del inferior, pero nada dice sobre el fondo del asunto ${ }^{50}$. En cambio, en nuestra opinión, la introducción del requisito de la «especial trascendencia constitucional» no convierte en discrecional la admisión ni tampoco, concretamente, la apreciación de si el referido requisito concurre o no. El Tribunal Constitucional está vinculado por el tenor literal del art. 50 LOTC, es decir, el Tribunal deberá juzgar si el asunto presenta o no «especial trascendencia constitucional» «atendiendo a su importancia para la interpretación de la Constitución, para su aplicación o para su general eficacia, y para la determinación del contenido y alcance de los derechos fundamentales». Se tratará de conceptos vagos, pero son conceptos legales. Los conceptos jurídicos indeterminados son solo indeterminados a priori, pero la aplicación de los mismos tiene solamente una solución justa que corresponde encontrar al órgano judicial. Además, puesto que el Tribunal ha decidido concretar qué significa tal concepto en la STC 155/2009, queda vinculado a su jurisprudencia en tanto no la revise. Puede reconsiderarla y revisarla, no incumplirla en un caso concreto. Por más que, efectivamente, la propia STC 155/2009 no ate estrechamente al Tribunal, por amplio que sea el margen de interpretación, no es lo mismo considerar que estamos ante un requisito reglado que ante una facultad discrecional. Sobre todo, si tenemos en cuenta que, cuando se emplea en este ámbito el término discrecional, no se está empleando como la doctrina administrativista lo emplea, sino afirmando una libérrima posibilidad de decisión que en absoluto estaría condicionada jurídicamente. La propia doctrina administrativista hace mucho tiempo que ha aceptado la idea de que el acto discrecional puro

49 En el año 2010, se pronunciaron 143 sentencias. De ellas, 113 en recursos de amparo: 18 fueron dictadas por el Pleno, 87 por las Salas y 8 por las Secciones. En el año 2011, el Tribunal dictó 207 sentencias. De ellas, 152 fueron correspondientes a recursos de amparo: 4 por el Pleno, 105 por las Salas y 43 por las Secciones. En el año 2012, nuestro Tribunal Constitucional aprobó 246 sentencias. De ellas, 144 recayeron en recursos de amparo: 34 fueron dictadas por el Pleno; las Salas dictaron 109 y la Sección cuarta dictó 1.

50 Esta es la posición ortodoxa del Tribunal sobre la explicación de su facultad para elegir los casos que se le plantean, que fue expresada por Frankfurter en el caso Maryland v. Baltimore Radio Show, Inc. (1950). La cuestión está exhaustivamente tratada en un artículo de Linzer que ya podemos considerar clásico: «The meaning of certiorari denials», en Columbia Law Review, vol. 79 [1979], pp. 1227 y ss. Véase, en este sentido, Ahumada Ruiz, M. Á., «El “certiorari”. Ejercicio discrecional de la jurisdicción de apelación por el Tribunal Supremo de Estados Unidos», Revista Española de Derecho Constitucional, año 14, núm. 41, mayo-agosto 1994, pp. 89 y ss., especialmente p. 135. 
no existe ${ }^{51}$, siendo necesario siempre tener en cuenta la existencia de ciertos elementos reglados, pues otra cosa resulta contraria al Estado de Derecho.

Ahora bien, una vez matizada la diferencia entre el sistema de Estados Unidos y el introducido por la Ley Orgánica de 2007, es preciso señalar que, aun así, en nuestra opinión, el Tribunal Constitucional durante cierto tiempo no aplicó la referida reforma en la medida en que el Tribunal concedía más relevancia de la que le correspondía a la vulneración del derecho fundamental. No es que seamos partidarios de una disminución de las garantías, es que sencillamente consideramos que esta fue la voluntad del legislador. De tal manera que si ese requisito no se da, aunque se hubiera producido la lesión subjetiva del derecho y sea cual sea la gravedad de la misma, el Tribunal no admitirá, y, en todo caso, no estimará el amparo ${ }^{52}$ ».

Desde luego, no resulta posible señalar con precisión las razones por las que nuestro Tribunal Constitucional no aplicó en los primeros años la reforma de 2007 hasta sus últimas consecuencias. Es de suponer que por una preocupación garantista, que podría concretarse en temor a las condenas del TEDH. Tal vez haya influido el temor a que el TEDH deje de reconocer el recurso de amparo ante el Tribunal Constitucional como remedio útil y, por tanto, como trámite necesario para agotar la vía judicial antes de acudir al TEDH ${ }^{53}$. Lo cierto es que la reforma de 2007 pretendía que el Tribunal tuviera las manos libres para resolver los conflictos de competencia y los recursos de inconstitucionalidad, esto es, los asuntos de Pleno. Y no se hacía del todo.

\section{SEGUNDO PERÍODO EN LA APLICACIÓN DE LA REFORMA DE 2007: DESDE LA STEDH ARRIBAS ANTÓN HASTA LA ACTUALIDAD}

1. La reforma de 2007 fue muy criticada por suponer disminución de garantías de los derechos fundamentales y la realidad es que no se aplicaba del todo. Durante varios años, cuando existía una vulneración clara de un derecho fundamental, el Tribunal parecía admitir asuntos sin «especial trascendencia constitucional» aunque no

51 García de EnTERria, E., La lucha contra las inmunidades del poder, Cuadernos Civitas, Aranzadi, 2016

52 Para decirlo con palabras del profesor y Magistrado Aragón Reyes, la tutela de los derechos fundamentales después de la reforma de 2007 por medio del recurso de amparo ante el Tribunal Constitucional «ya no estará únicamente vinculada, como hasta antes de la reforma, a que se haya producido la lesión subjetiva del derecho, sino que solo se otorgará si a esa lesión subjetiva se une un indispensable requisito objetivo: que el problema planteado posea una "especial trascendencia constitucional”". ARAGón Reyes, M., «La reforma de la Ley Orgánica del Tribunal Constitucional», en Revista Española de Derecho Constitucional, número 85, Madrid, 2009, pp. 11 y ss., especialmente p. 40.

53 Hasta la fecha, como hemos visto con anterioridad, el TEDH, en su Decisión de 25 de septiembre de 2012, asunto Pedro María Bereza Oroquieta c. España, no ha considerado que el recurso de amparo no sea remedio útil y ha considerado que el hecho de que se decida la inadmisión del recurso de amparo por falta de especial trascendencia constitucional mediante providencia que se limite a expresar que concurre tal defecto no vulnera el art. $6 \mathrm{CEDH}$. 
se reconociera así en su doctrina. Ahora bien, esto se podía hacer porque en la posterior Sentencia del Tribunal no se expresaba el motivo concreto por el que se había considerado que concurría el requisito de la «especial trascendencia constitucional».

Sin embargo, el Tribunal Europeo de Derechos Humanos, en la Sentencia Arribas Antón, probablemente con voluntad de garantizar mejor los derechos, señaló que era mala técnica de administración de justicia no expresar el motivo de especial trascendencia constitucional.

En efecto, en la STEDH de 20 de enero de 2015, caso Arribas Antón v. España, n. ${ }^{\circ}$ 16563/11, el TEDH consideró que no hay violación del art. 6.1 CEDH ni del art. 13 CEDH por parte de la Ley Orgánica 6/2007, de 24 de mayo, que introdujo el requisito de la especial trascendencia constitucional para la admisión del recurso de amparo, pero de alguna manera el TEDH hace un apercibimiento velado al Tribunal Constitucional por no estar satisfaciendo el principio de buena administración de justicia en la aplicación de su doctrina constitucional, lo que demuestra con un minucioso estudio de su jurisprudencia. El TEDH sostiene que el Tribunal Constitucional debe explicitar el motivo de especial trascendencia constitucional que concurre en los recursos declarados admisibles. Tendrá que justificar, a raíz de la intervención del TEDH, el motivo concreto concurrente de especial trascendencia constitucional.

Naturalmente, nuestro supremo garante de los derechos, que se esmera en acatar la doctrina del TEDH, se dispuso a expresar en todas sus Sentencias de amparo el motivo de especial trascendencia constitucional.

La primera resolución dictada por nuestro Alto Tribunal tras la STEDH Arribas Antón v. España fue la STC 9/2015, de 2 de febrero, en la que recoge la advertencia del TEDH, en el FJ 3. Y a partir de esa decisión, nuestro Tribunal Constitucional, en acatamiento de la doctrina del TEDH, explicita y motiva, por regla general, la admisión de cada recurso de amparo, unas veces en los antecedentes y otras en los fundamentos jurídicos. Ya en la presentación de la Memoria 2014, el Presidente del Tribunal Constitucional afirmó que desde la STEDH Arribas Antón v. España, la causa de especial trascendencia constitucional de cada asunto admitido, deberá expresarse en las providencias de admisión a trámite y que la referencia a éstas últimas se incluirá en los antecedentes de hecho de las sentencias.

No obstante, analizando las sentencias publicadas en la página web del Tribunal Constitucional hasta el 2 de octubre de 2016, Hernández Ramos constata que el Tribunal no motivó la admisión en los algunos $\operatorname{casos}^{54}$. De las Memorias del Tribu-

54 V. Hernández Ramos, M., «Incumplimiento de la buena administración de justicia del Tribunal Constitucional en la admisión del recurso de amparo. El caso Arribas Antón vs. España del TEDH», en REDC , n. ${ }^{\circ} 108$, año 36, septiembre/diciembre 2016, páginas 307 y siguientes, que cita las siguientes sentencias: SSTC 78/2015, de 30 de abril; 80/2015, de 30 de abril; 82/2015, de 30 de abril; 90/2015, de 11 de mayo; 91/2015, de 11 de mayo; 112/2015, de 8 de junio; 146/2015, de 6 de julio; 150/2015, de 6 de julio; 177/2015, de 22 de julio; 179/2015, de 7 de septiembre; 183/2015, de 10 de septiembre; 187/2015, de 21 de septiembre; 24/2016, de 15 de febrero, todo lo cual supone un 14,7\% de los casos que analiza el referido autor. 
nal Constitucional de los años 2015 y 2016 (cuadros 2 y 3 del presente trabajo) se desprende que, desde que se inició la práctica de expresar en la providencia de admisión el motivo de especial trascendencia constitucional, solo se han producido trece providencias sin indicación de motivos. Todas las demás expresan los motivos. En particular, en el año 2016 no hubo ninguna que no lo expresara. Otra cosa es que la cuestión no se explique en la correspondiente sentencia. Normalmente, en las Sentencias del Tribunal, en un antecedente de hecho, se hace referencia a la providencia de admisión así como al motivo en que la misma se basó. Pero en algunas ocasiones se dice lo que adujo la demanda y luego se dice que el asunto fue admitido sin reproducir el motivo que reflejó la providencia de admisión.

Pero la STEDH Arribas Antón acabó teniendo un resultado contrario al fin que pretendía, pues nuestro Tribunal Constitucional, al verse obligado a expresar en sus sentencias el motivo de «especial trascendencia constitucional», decidió considerar sólo la «especial trascendencia constitucional» alegada por el recurrente y además pasó a considerarla con anterioridad al requisito de la existencia de vulneración del derecho fundamental.

2. La intervención del TEDH tuvo un efecto probablemente no querido. Si el TEDH había intervenido con ánimo garantista, el resultado ha sido que nuestro Tribunal Constitucional ha pasado a examinar ante todo, la «especial trascendencia constitucional», y si no concurre este requisito, no pasa a analizar si existe vulneración de derecho fundamental. Además, el Tribunal solo se plantea si concurre la «especial trascendencia constitucional» alegada por el recurrente.

Ha existido, pues, evolución por lo que se refiere al orden en que se analizan los requisitos. En un primer periodo, el Tribunal comenzaba el examen de admisibilidad por verificar si existía o no verosimilitud de la lesión para a continuación juzgar si el asunto revestía «especial trascendencia constitucional»o no. Así parece desprenderse de los AATC 135 a 147/2011, que inadmiten por ausencia de derecho amparable ${ }^{55}$ recursos que, por su similitud con el contemplado en la STC 2001/2011, debemos considerar que cumplen el requisito de la «especial trascendencia constitucional» ${ }^{56}$, así como del ATC 9/2012, que decidió la inadmisión por falta de lesión de derecho constitucional amparable ${ }^{57}$.

55 Art. 50.1.a LOTC.

56 Requejo Pagés, J. L., «Doctrina del Tribunal Constitucional durante el Primer cuatrimestre de 2011»REDC, núm. 94, enero-abril 2012, pp. 291 y ss. y GonZÁlez Alonso, A. «¿Ha cambiado algo el recurso de amparo tras la aprobación de la LO 6/2007, de 24 de mayo?», en Justicia Administrativa. Revista de Derecho administrativo, n. 59, 2013, pp., 17 y ss., especte. p.28

57 Requejo Pagés, J. L., «Doctrina del Tribunal Constitucional durante el Primer cuatrimestre de 2012» Revista Española de Derecho Constitucional, núm. 95, mayo-agosto 2012, pp. 266-269; concretamente, se señala que en los AATC 134/2011 a 144/2011, y probablemente en el ATC 9/2012 el Tribunal comienza el examen de la admisibilidad de la demanda verificando la efectiva concurrencia de la lesión del derecho fundamental invocado — es decir, anticipando un juicio sobre el fondo — reservando el juicio sobre la transcendencia constitucional para el caso en que se hubiera advertido que el derecho 
Pero en un momento posterior, el análisis comienza por la especial trascendencia constitucional, como se desprende de la existencia de providencias de inadmisión que se fundamentan solamente en la ausencia de «especial trascendencia constitucional». ${ }^{58}$ La existencia de asuntos en que se haya vulnerado un derecho fundamental y en los que el Tribunal Constitucional no entra a considerarlo ha dejado de ser una posibilidad teórica y es una posibilidad sumamente real. Si se constata que la «especial trascendencia constitucional» no concurre, ni siquiera se estudia si ha habido o no vulneración de derechos fundamentales. Por tanto, ya es perfectamente posible que un asunto contenga una violación de derechos fundamentales y sin embargo no sea admitido.

3. De esta manera, se progresa en el sentido de reconocer el carácter reglado tanto de la admisión como en particular del requisito de la «especial trascendencia constitucional», que no puede ser una fuente de discrecionalidad para el Tribunal, sino que, al mismo tiempo que lo habilita, lo limita.

4. Se reconoce que puede haber vulneración de derecho fundamental y, sin embargo, proceder a la inadmisión del recurso de amparo. Los cuadros y las Memorias del Tribunal Constitucional en los que aparece como motivo de inadmisión posible la falta de especial trascendencia constitucional así lo muestran.

Parece que providencias de inadmisión que se fundamenten exclusivamente en la ausencia de especial transcendencia constitucional existen solo desde el año 2014, en el que hubo 17 inadmisiones basadas en este motivo de un total de 6662, es decir, solo el 0,25\% del total de las inadmisiones de recursos de amparo.

5. Se podría pensar que, ante las críticas por la disminución de garantías que ha supuesto esta reforma de la LOTC (de 2007) y dado que esta reforma se planteó porque el Alto Tribunal no daba abasto con el trabajo que tenía que atender y esa situación ha desaparecido, este requisito podría desaparecer. En efecto, nuestro Tribunal Constitucional venía haciendo un gran esfuerzo para ponerse al día en las materias del Pleno, lo que estaba consiguiendo a grandes pasos, y además, se había puesto al día

en cuestión ha sido lesionado realmente, ya que el Tribunal no se limita a un examen indiciario, sino que por ejemplo en el ATC 9/2012 se adentra de manera exhaustiva en todos los aspectos de la cuestión de fondo. V. asimismo GonzÁlez Alonso, A. «¿Ha cambiado algo el recurso de amparo tras la aprobación de la LO 6/2007, de 24 de mayo?», en Justicia Administrativa. Revista de Derecho administrativo, n. 59, 2013, pp., 17 y ss., especte. p. 29.

58 Así, en la Memoria del Tribunal Constitucional correspondiente al año 2016 consta que fueron inadmitidos por falta de especial transcendencia constitucional 662 asuntos sobre un total de 4230, es decir, el 15,65\% de los recursos de amparo inadmitidos. En la Memoria correspondiente al año 2014 fueron solamente 17 los recursos de amparo inadmitidos por falta de especial transcendencia constitucional, sobre un total de 6662 asuntos inadmitidos, es decir, el $0,25 \%$. No podemos saber o que ocurrió en años anteriores porque la Memoria de 2013 no incluía un cuadro en el que figuraran estadísticas de las inadmisiones por razón de la fundamentación de las mismas. 
en el ámbito del recurso de amparo. Esto se estaba haciendo porque la reforma de 2007, aunque hubiera sido realizada como es lógico a través de una Ley orgánica, había sido de manera informal alentada e incluso solicitada por Magistrados del Alto Tribunal. En estos últimos existía de alguna forma la conciencia de que se trataba de un remedio excepcional hasta que se pusiera el Tribunal al día.

Pero en la actualidad la situación ha cambiado. El requisito de la especial trascendencia constitucional está firmemente asentado. No solamente en la jurisprudencia de nuestro supremo intérprete de la Constitución. Hay más indicios que hacen pensar que este tipo de requisitos se van a consolidar. Los vientos no son favorables para la supresión de este requisito.

En este sentido, en primer lugar, debemos recordar que el Tribunal de Justicia de la Unión Europea aceptó el criterio de la Comisión cuando esta última decidió seleccionar las quejas de los particulares sobre vulneraciones del derecho de la competencia con base en el interés que tuvieran para la interpretación del Derecho de la Unión Europea ${ }^{59}$. Ha de destacarse que en aquel caso la Comisión había adoptado tal postura sin previo cambio normativo del Derecho de la Comunidad y a pesar de ello su proceder fue convalidado judicialmente.

En segundo lugar, debemos hacer referencia al establecimiento de un requisito similar para acceder al Tribunal Europeo de Derechos Humanos ${ }^{60}$. En efecto, el artículo 35.3 del CEDH, establece en la actualidad lo siguiente:

59 La cuestión se planteó en 1990. La planteó Automec, una sociedad italiana que recurrió ante el Tribunal de Primera Instancia la Decisión de la Comisión de seleccionar las quejas en función de su relevancia para la interpretación del Derecho de la Comunidad. El Tribunal de Primera Instancia, en STJUE-TPI de 10 de julio de 1990, inadmitió el recurso. Pero el asunto se recurrió ante el Tribunal General. Las conclusiones del Juez D. A. O. Edward, en funciones de Abogado General, firmadas el 10 de marzo de 1992, propusieron la desestimación del recurso y el Tribunal General, en STJUE-TPI-TG de 18 de septiembre de 1992, desestimó el recurso, dando por buena la actuación de la Comisión.

${ }^{60}$ A lo que decimos en el texto, debe añadirse que el TEDH reformó el artículo 47 de su Reglamento en 2013 endureciendo los requisitos formales. El nuevo artículo 47 entró en vigor el 1 de enero de 2014. Esta modificación del Reglamento, que tiene como objetivo acrecentar la eficacia del TEDH y acelerar el examen de las demandas, aporta dos cambios esenciales que determinaran si una demanda es atribuida a un Tribunal colegiado o si es rechazada sin ser examinada por el TEDH. El primer cambio a cumplir está relacionado con las informaciones y documentos aportados al TEDH para que pueda examinar las demandas con facilidad y cumplir así su cometido de la manera más eficiente: cualquier formulario enviado al TEDH deberá ser cumplimentado en su integridad y acompañado de las copias de los documentos pertinentes; toda demanda incompleta será rechazada por el TEDH. El segundo cambio a cumplir concierne a la interrupción del plazo en el que se debe presentar la demanda ante el TEDH, es decir, dentro de los 6 meses siguientes a la decisión firme dictada por la más alta jurisdicción interna competente; con el fin de que este plazo se interrumpa, se necesita, a partir de ahora, que la demanda cumpla todos los requisitos enumerados en el artículo 47 del Reglamento. El formulario debe ser enviado al TEDH debidamente cumplimentado y acompañado de los documentos pertinentes en el plazo previsto por el Convenio. No se tendrá ya en cuenta por tanto un expediente incompleto para interrumpir el plazo de 6 meses. 
«3. El Tribunal declarará inadmisible cualquier demanda individual presentada en virtud del artículo 34 si considera que: a) la demanda es incompatible con las disposiciones del Convenio o de sus Protocolos, manifiestamente mal fundada o abusiva; o b) el demandante no ha sufrido un perjuicio importante, a menos que el respeto de los derechos humanos garantizados por el Convenio y por sus Protocolos exija un examen del fondo de la demanda, y con la condición de que no podrá rechazarse por este motivo ningún asunto que no haya sido debidamente examinado por un Tribunal nacional.»

Por otra parte, y ello resulta digno de lamentar, también en el ámbito de la justicia ordinaria, concretamente en las jurisdicciones contencioso-administrativa, civil y penal, se ha introducido un requisito de admisión del recurso de casación denominado «interés casacional» inspirado en el requisito de la especial trascendencia constitucional. Lo que además complica la determinación del correcto agotamiento de la vía judicial previa al recurso de amparo ante el supremo garante de los derechos fundamentales. Sobre esta cuestión volveremos más adelante.

6. En la fase analizada se avanza en la interpretación de los diferentes motivos de especial trascendencia constitucional.

En un primer periodo no era fácil conocer, más allá de estos criterios generales, cómo se concretaba la «especial trascendencia constitucional». Esto se debía a que la misma se exige en fase de admisión, la cual se resuelve mediante providencia, es decir, resolución judicial no motivada. Nuestro Alto Tribunal pocas veces tenía que explicitar en sentencia las razones que le habían llevado a considerar que el recurso cumplía el repetido requisito. No obstante, hubo algunas sentencias en que se expresó el motivo concreto, dentro de los especificados en la STC 155/2009, de «especial trascendencia constitucional». Concretamente, se tenía que aludir a la «especial trascendencia constitucional» cuando en las alegaciones de las partes que se presentan una vez admitida la demanda se adujera, o bien falta de justificación de la «especial trascendencia constitucional» (STC 32/2013, de 11 de febrero, FJ 2) o falta de «especial trascendencia constitucional» (para desestimar el óbice). También había que explicitar el juicio sobre la «especial trascendencia constitucional» del recurso cuando el Tribunal considerara que debe incluir un supuesto al margen del elenco contenido en las SSTC 70 y 155/2009. O cuando el Ministerio Fiscal recurriera en súplica la providencia de inadmisión basada en la falta de «especial trascendencia constitucional» porque, según el Ministerio Fiscal, sí concurren ${ }^{61}$.

Resulta muy interesante analizar la jurisprudencia posterior a la STEDH Arribas Antón o a la STC 9/2015 de 2 de febrero, (que incorporó la doctrina de la STEDH), para intentar deducir cuáles son los motivos de especial trascendencia constitucional que dan lugar a un mayor número de admisiones de recursos de amparo.

${ }^{61}$ AATC 185/2011, de 21 de diciembre; 11/2012, de 26 de enero; 123/2012, de 18 de junio. 
Ahora bien, debe advertirse que todo análisis estadístico, aunque pueda servir de alguna orientación a los abogados de los justiciables, no establece necesidades lógicas. Es decir, un recurso de amparo no tiene más probabilidades de ser admitido porque aduzca, por ejemplo, la necesidad de aclarar la doctrina del Tribunal Constitucional (motivo que, como veremos, es el que da de hecho, lugar a más admisiones) que cualquier otro motivo de especial trascendencia constitucional, sino que la admisión depende de que el motivo aducido concurra efectivamente o no.

Hernández Ramos ${ }^{62}$ ofrece un análisis de los motivos de especial trascendencia constitucional por los que habían sido admitidas las sentencias de nuestro Tribunal Constitucional dictadas desde enero de 2015 hasta 2 de octubre de 2016, ofreciendo el porcentaje de casos en que se aceptó la concurrencia de los diferentes motivos sistematizados por la STC 155/2009. De ese análisis se desprende que los dos motivos que más admisiones suelen fundamentar son la aclaración de la propia doctrina del Tribunal Constitucional (supuesto b del FJ 2 de la STC 155/2009) y la presencia de nuevas facetas de derechos fundamentales (supuesto a del FJ 2 de la STC 155/2009) Estos dos supuestos que acabamos de aludir supondrían casi el $58 \%$ del total de las sentencias examinadas.

El análisis de los motivos de especial trascendencia constitucional que dio lugar a la admisión de los recursos de amparo que se resolvieron con posterioridad al estudio de Hernández Ramos, también muestra que el motivo más aceptado por el que el Tribunal Constitucional considera que concurre especial trascendencia constitucional es la necesidad de aclarar su propia doctrina. En efecto, hasta donde hemos alcanzado a ver, después de 2 de octubre de 2016, nuestro Tribunal Constitucional ha dictado 32 sentencias correspondientes al motivo de especial trascendencia constitucional recogido en el apartado b) del FJ2 de la STC 155/200963, cifra que supera en mucho la suma de las dictadas por los otros motivos de especial trascendencia constitucional recogidos en el FJ 2 de la STC 155/2009 ${ }^{64}$

62 V. Hernández Ramos, M., «Incumplimiento de la buena administración de justicia del Tribunal Constitucional en la admisión del recurso de amparo. El caso Arribas Antón vs. España del TEDH», en REDC, n. ${ }^{\circ} 108$, año 36, septiembre/diciembre 2016, páginas 307 y siguientes

63 SSTC: 163/2016, de 3 de octubre; 173/2016, de 17 de octubre; 176/2016, de 17 de octubre; 189/2016, de 14 de noviembre; 200/2016, de 28 de noviembre; 201/2016, de 28 de noviembre; 206/2017, de 12 de diciembre; 207/2016, de 12 de diciembre; 208/2016, de 12 de diciembre; 209/2016, de 12 de diciembre; 212/2016, de 15 de diciembre; 218/2016, de 19 de diciembre; 221/2016, de 19 de diciembre; 222/2016, de 19 de diciembre; 223/2016, de 19 de diciembre; 1/2017, de 16 de enero; $2 / 2017$, de 16 de enero; 3/2017, de 16 de enero; 4/2017, de 16 de enero; $11 / 2017$, de 30 de enero; 12/2017, de 30 de enero; 14/2017, de 30 de enero; 31/2017, de 27 de febrero; 38/2017, de 24 de abril; 42/2017, de 24 de abril; 74/2017, de 19 de junio; 75/2017, de 19 de junio; 83/2017, de 3 de julio; 84/2017, de 3 de julio; 85/2017, de 3 de julio; 105/2017, de 18 de septiembre; 112/2017, de 16 de octubre

${ }^{64}$ En algunos casos no se expresa el motivo que fundamentó la providencia de admisión pero se recoge la fundamentación al respecto de la demanda: SSTC 161/2016, de 3 de octubre; 166/2016, de 6 de octubre; 172/2016, de 17 de octubre o 226/2016, de 22 de diciembre. 
En la actualidad, contamos con una fuente muy relevante para hacer un análisis de este tipo. Las Memorias del Tribunal Constitucional de los años 2015 y 2016 incluyen sendos cuadros en los que se recoge el número de recursos que han sido admitidos por los diferentes motivos que allí se reflejan (que se basan en, aunque no coinciden con, los diferentes apartados el FJ 2 de la STC 155/2009) y así mismo el porcentaje del total de asuntos admitidos que representa cada uno de esos números absolutos.

Por no ser estos cuadros muy extensos y considerarlos de sumo interés para el presente trabajo lo reproducimos a continuación como cuadro número 2 y cuadro número 3.

Cuadro 2. Recursos admitidos por el Tribunal Constitucional por los diferentes motivos de especial trascendencia constitucional en el año 2015

\begin{tabular}{lrr}
\multicolumn{1}{c}{ Motivos de admisión } & Recursos & Porcentaje \\
\hline Ausencia de doctrina constitucional & 20 & 22,98 \\
$\begin{array}{l}\text { Aclaración o cambio de doctrina, consecuencia } \\
\text { de un proceso de reflexión interna }\end{array}$ & 10 & 11,49 \\
$\begin{array}{l}\text { Aclaración o cambio de doctrina, consecuencia } \\
\text { de nuevas realidades sociales }\end{array}$ & 2 & 2,29 \\
$\begin{array}{l}\text { Aclaración o cambio de doctrina, consecuencia } \\
\text { de cambios normativos }\end{array}$ & 12 & 13,79 \\
$\begin{array}{l}\text { Eventual origen normativo de la vulneración } \\
\begin{array}{l}\text { Incumplimiento general y reiterado de la } \\
\text { doctrina constitucional, resoluciones judiciales }\end{array}\end{array}$ & 1 & 1,15 \\
contradictorias & 11 & 12,65 \\
Repercusión social o económica & 1 & 1,15 \\
Consecuencias políticas generales & 4 & 4,60 \\
Varios motivos & 13 & 14,95 \\
Sin indicación de motivos & 13 & 14,95 \\
\hline Total & $\mathbf{8 7}$ & $\mathbf{1 0 0}$ \\
\hline
\end{tabular}


Cuadro 3. Recursos admitidos por el Tribunal Constitucional por los diferentes motivos de especial trascendencia constitucional en el año 2016

\begin{tabular}{lcc}
\multicolumn{1}{c}{ Motivos de admisión } & Recursos & Porcentaje \\
\hline Ausencia de doctrina constitucional & 12 & 17,91 \\
$\begin{array}{l}\text { Aclaración o cambio de doctrina, consecuencia } \\
\text { de un proceso de reflexión interna }\end{array}$ & 17 & 25,37 \\
$\begin{array}{l}\text { Aclaración o cambio de doctrina, consecuencia } \\
\text { de cambios normativos }\end{array}$ & 3 & 4,48 \\
$\begin{array}{l}\text { Eventual origen normativo de la vulneración } \\
\text { Eventual vulneración por reiterada interpreta- }\end{array}$ & 8 & 11,94 \\
ción jurisprudencial de la ley & 3 & 4,48 \\
$\begin{array}{l}\text { Incumplimiento general y reiterado de la } \\
\text { doctrina constitucional, resoluciones judiciales } \\
\text { contradictorias }\end{array}$ & 1 & 1,49 \\
$\begin{array}{l}\text { Eventual negativa al acatamiento de doctrina } \\
\text { constitucional por resoluciones judiciales }\end{array}$ & 9 & 13,43 \\
Repercusión social o económica & 2 & 2,99 \\
Consecuencias políticas generales & 4 & 5,97 \\
Varios motivos & 8 & 11,94 \\
Sin indicación de motivos & - & - \\
\hline Total & $\mathbf{6 7}$ & $\mathbf{1 0 0}$ \\
\hline
\end{tabular}

Destacaremos tan solo que en el año 2015, la necesidad de formular doctrina constitucional fundamentó casi el $23 \%$ de las admisiones y la aclaración o cambio de doctrina (en la que el cuadro subdistingue 3 tipos) dio lugar al 47,6\% de las admisiones, siendo estos motivos los que dieron lugar a un porcentaje mayor de admisiones. En el año 2016 los dos motivos que dieron lugar a mayor porcentaje de admisiones fueron también la ausencia de doctrina constitucional (casi el 18\% del total) y la aclaración de la doctrina del propio Tribunal (dentro de la que se subdistinguen dos categorías) que dio lugar al $30 \%$ de las admisiones aproximadamente.

Por lo demás, consolidado el requisito de la «especial trascendencia constitucional», se plantea el reto de concretar los diferentes supuestos. En este sentido, ha de indicarse que el Tribunal Constitucional considera que acudir indebidamente a 
la comunicación edictal es una vulneración de derecho fundamental que puede reconducirse al supuesto de incumplimiento reiterado de la doctrina del Tribunal Constitucional por parte de la jurisdicción ordinaria (STC 180/2015, de 7 de septiembre) ${ }^{65}$ o a la necesidad de aclarar de aclarar doctrina (STC 181/2015, de 7 de septiembre) $)^{66}$.

También debe reseñarse la precisión de que la negativa manifiesta a acatar la doctrina del Tribunal Constitucional puede ser implícita (SSTC 5/2017, de 16 de enero $^{67}$, y 6/2017, de 16 de enero ${ }^{68}$ ), ambas relativas también al emplazamiento por edictos. En efecto, en su Voto Particular a la STC 11/2016, de 1 de febrero, la magistrada Roca Trías planteó que rara vez un órgano judicial, de manera explícita, se niega a acatar la doctrina del Tribunal Constitucional. Esta línea de razonamiento se convertirá en doctrina del Tribunal en las Sentencias que acabamos de citar. El Alto Tribunal considera que es posible calificar una falta de acatamiento de su doctrina en la que incurra un órgano judicial como manifiesta, aunque sea implícita, si se aprecia que el Tribunal ordinario tiene voluntad de no respetar una doctrina del Tribunal Constitucional que conoce. Se trataría de un incumplimiento consciente y deliberado, a sabiendas de que el supremo garante de los derechos fundamentales mantiene una doctrina contraria a su postura.

7. En ocasiones, el Tribunal Constitucional admite un asunto para formular doctrina o para aclararla y luego no procede a la formulación de la doctrina correspondiente, lo que se le ha reprochado. Pero este reproche no está justificado en nuestra opinión.

65 En la STC 180/2015, de 7 de septiembre, se otorgó el amparo por vulneración del derecho a la tutela judicial efectiva (acceso al recurso): inadmisión sin motivación de un incidente de nulidad de actuaciones (STC 142/2015). La especial trascendencia constitucional del asunto estriba en que la doctrina del Tribunal Constitucional sobre el derecho fundamental que se alega podría estar siendo incumplida de modo reiterado por la jurisdicción ordinaria.

${ }^{66}$ En la STC 181/2015, de 7 de septiembre, se otorgó el amparo por vulneración del derecho a la tutela judicial sin indefensión: emplazamiento mediante edictos del demandado, cuyo domicilio y correo electrónico figuraban en la documentación obrante en autos (STC 30/2014). La especial trascendencia constitucional reside en la necesidad de aclarar la doctrina en relación a la reforma introducida por la Ley 19/2009 sobre la debida diligencia de los órganos judiciales en el emplazamiento y notificación a las partes en un procedimiento.

${ }^{67}$ En la STC 5/2017, de 16 de enero, se otorgó el amparo por vulneración del derecho a la tutela judicial sin indefensión: emplazamiento mediante edictos de demandado cuyo domicilio figuraba en la documentación aportada con la demanda (STC 122/2013). La especial trascendencia constitucional reside en que el órgano judicial puede haber incurrido en una negativa manifiesta del deber de acatamiento de la doctrina del Tribunal.

${ }^{68}$ En la STC 6/2017, de 16 de enero, se otorgó el amparo por vulneración del derecho a la tutela judicial sin indefensión: emplazamiento mediante edictos de demandado cuyo domicilio figuraba en la documentación aportada con la demanda (STC 122/2013). La especial trascendencia constitucional reside en que el órgano judicial puede haber incurrido en una negativa manifiesta del deber de acatamiento de la doctrina del Tribunal. 
Ha de observarse que el hecho de que el Tribunal admita un asunto por considerar que le da ocasión de aclarar o cambiar su doctrina, no quiere decir que en todo caso la aclaración o cambio de doctrina se produzca de manera efectiva. Esto no solo es comprensible, sino que es una consecuencia lógica de que la «especial trascendencia constitucional» es un requisito que se tiene en cuenta solo en el momento de la admisión a trámite y por el órgano que toma la correspondiente decisión (Sección o Sala).

Es comprensible, decimos, si tenemos en cuenta que las sentencias las dictan o las pueden dictar Magistrados distintos de los que decidieron la admisión. Los Magistrados que dictan las sentencias no pueden adivinar por qué se admitió determinado recurso de amparo, ya que la providencia de admisión, como providencia que es, no es motivada y hace referencia sucinta al motivo por el que se admite. Pero es que además los Magistrados que dictan la sentencia no tienen que plantearse si existe o no «especial transcendencia constitucional». Por tanto, ni siquiera tiene sentido plantearse que puedan discrepar con las razones por las que se admitió el recurso. Pero obviamente, si consideran que no hay doctrina que aclarar, no proceden a aclararla.

\section{BALANCE DE LA APLICACIÓN DE LA REFORMA DE 2007 DIEZ AÑOS DESPUÉS DE SU PROMULGACIÓN}

1. La interpretación y aplicación de la reforma de 2007 que ha hecho el Tribunal Constitucional no parece objetable ni desde el punto de vista de la legalidad ni desde la perspectiva de la constitucionalidad. A lo largo de este trabajo, hemos visto cómo nuestro supremo garante de los derechos fundamentales ha ido matizando su doctrina manteniendo la coherencia de la misma.

Para aplicar en rigor la reforma de 2007, resultaba necesario llevar hasta sus últimas consecuencias la idea de que, aunque un asunto presente una vulneración de un derecho fundamental, si no tiene «especial trascendencia constitucional», no puede ser admitido.

Solo nos queda una objeción. La supuesta discrecionalidad para decidir la «especial trascendencia constitucional». Que no es poco. Porque, en cierta manera, parece una pieza coherente con todo un edificio: ensambla con la concepción de la «especial trascendencia constitucional» como un requisito que solo se tiene en cuenta en la fase de admisión y quizás ha influido en la necesidad de construir la distinción entre el requisito consistente en justificar suficientemente la «especial trascendencia constitucional», por una parte, y la concurrencia de «especial trascendencia constitucional», por otra.

2. En la actualidad podemos decir que desde el punto de vista de la legalidad la reforma de 2007 se aplica en su plenitud. 
Hay que aceptar la objetivación del amparo. Frente a las críticas formuladas desde una perspectiva garantista, hay que señalar que la garantía de los derechos corresponde a la totalidad del Poder Judicial y que un tribunal de carácter supremo no puede atender todas las quejas que se producen en un país. Ha habido una evolución análoga en Estados Unidos o en Alemania. Como hemos visto, también el Tribunal Europeo de Derechos Humanos y el Tribunal de Justicia de la Unión Europea han aceptado medidas semejantes. El primero rechaza liminarmente todas las demandas que no cumplan exhaustivamente los requisitos formales.

Es cierto sin embargo que mientras el acceso a la instancia revisora esté concebido como una garantía del derecho de quien es parte en un proceso de obtener una decisión judicial correcta, cualquier restricción del acceso puede verse como una limitación de tal garantía y, consiguientemente, como una rebaja de la eficacia del derecho del justiciable.

3. Teniendo en cuenta que uno de los objetivos principales de la reforma de 2007 era resolver el posible colapso del Tribunal Constitucional, podemos afirmar que dicha reforma ha producido buenos resultados.

Basta volver al cuadro número 1 de este trabajo y comparar la situación del Tribunal Constitucional en 2006 y en 2016. A la de 2006 hicimos referencia anteriormente: era una situación próxima al colapso, de inviabilidad. A finales de 2016, en cambio, solo había 2358 recursos de amparo pendientes de resolución sobre la admisión (menos de la mitad de los que se presentan en un año), solo 88 sentencias de amparo pendientes de ser dictadas (cantidad equiparable al número de sentencias de amparo que en la actualidad se vienen a dictar en un año) y solo había 160 sentencias de Pleno pendientes (cifra aproximadamente equivalente al número de sentencias de pleno que se dictan en la actualidad en año y medio). Desde este punto de vista, el tiempo de respuesta del Tribunal a los asuntos que se le plantean resulta ya aceptable.

4. Ciertamente, todavía se podría sostener que la reforma no ha sido un éxito al cien por cien. En efecto, si recordamos que el objetivo era un Tribunal que fuera al día, volcado en los asuntos de pleno y que solo dictara unas diez sentencias de amparo al año, eso no se ha conseguido. Pero tampoco se ve la necesidad de hacerlo, es decir, de reducir el número de sentencias de amparo anuales a diez.

5. Desde luego, no ha pasado lo que ocurrió con una reforma similar en Alemania.

Entre nosotros ${ }^{69}$, se ha señalado que la falta de aplicación de reformas parecidas en Alemania ha situado al Tribunal Constitucional alemán en una difícil encrucijada.

69 Hernández Ramos, M., «El Tribunal Constitucional alemán aun en la encrucijada, balance de medio siglo de reformas del trámite de admisión de la Verfassunsbeschwerde», en Revista Española de Derecho Constitucional, núm. 88, enero-abril (2010), pp. 83 y ss., especialmente p. 121. 
Al parecer, ante una situación de sobrecarga de trabajo similar a la que provocó la reforma de nuestra Ley Orgánica de 2007, en Alemania se introdujeron reformas en 1993 que tuvieron una notable eficacia para aumentar el número de asuntos resueltos. Se reconoce que la referida reforma evitó el colapso del Tribunal alemán. Pero la idea de que los Magistrados constitucionales alemanes no han aprovechado al máximo las posibilidades que ofrecía la reforma de 1993 ha sido defendida por importantes sectores de la doctrina alemana y por la Comisión Benda. Los márgenes que abrió la reforma no han sido suficientemente aprovechados debido a la concepción de la Verfassunsbeschwerde como instrumento de tutela jurídica subjetiva por parte de los Magistrados constitucionales. El Tribunal Constitucional Federal alemán tenía en 2010 un número de asuntos pendientes solo ligeramente inferior al que provocó la creación de la Comisión Benda. La reducción de la carga de trabajo del Tribunal alemán es muy tenue. Esto sitúa en una posición muy difícil al Tribunal Constitucional Federal alemán.

Por eso creemos que no bastaba con distinguir tajantemente entre vulneración del derecho fundamental y justificación de la «especial trascendencia constitucional» sino que había que aplicar con coherencia la consecuencia de tal distinción, que sería, en nuestro caso, admitir la posibilidad de que asuntos que presenten vulneración de derecho fundamental pueden no ser admitidos por falta de «especial trascendencia constitucional».

La reforma de 2007 fue, de alguna manera, una concesión que hizo el legislador al Tribunal Constitucional para que pudiera afrontar la extraordinaria sobrecarga de trabajo que tenía ${ }^{70}$. Si el Tribunal no la aplica, no podrá justificar su eventual colapso o el retraso en resolver los diferentes asuntos de que conoce.

6. Se podría objetar que hacer balance de la aplicación de la reforma de 2007 exigiría analizar si durante estos diez años realmente se han dictado por el Tribunal Constitucional solamente Sentencias «testigo», con influencia en la doctrina general del Tribunal, más allá del caso concreto resuelto ${ }^{71}$. Ciertamente, la reforma partía del

${ }^{70}$ Se puede constatar, por ejemplo, en la Memoria de 2006. La entonces Presidenta del Tribunal Constitucional, María Emilia Casas Baamonde, en la presentación de la Memoria, tras repasar sucintamente las diferentes cifras de asuntos ingresados y pendientes en el Tribunal, decía que los desajustes de las cifras ponían en evidencia, año tras año, con una tendencia inequívoca, confirmando un diagnóstico que no admitía controversia alguna, que era necesario, de manera perentoria, la intervención del legislador orgánico. Tribunal Constitucional. Memoria 2006, Tribunal Constitucional, Madrid, 2007 , p. 11.

71 Por ejemplo, la STC 39/2016, de 3 de marzo, (tratamiento de datos del personal sin informarle). Acerca de esta STC, v. Hernández Corchete, J, A., «Transparencia en la información al interesado del tratamiento de sus datos personales y en el ejercicio de sus derechos», en Reglamento General de Protección de Datos. Hacia un nuevo modelo europeo de privacidad (Dir. Piñar Mañas), Editorial Reus, 2016, pp., 210 y 211, con observaciones que de alguna manera anticipan el criterio de la STEDH de 9 de enero de 2018, asunto López Ribalda. 
presupuesto según el cual ya existía una doctrina constitucional consolidada sobre derechos fundamentales que la jurisdicción ordinaria aplicaba con regularidad. Y por ello, se pretendía reservar al Tribunal Constitucional para aquellos asuntos que, además de presentar vulneración de un derecho fundamental, supusieran novedad o elemento trascendente del caso concreto. En consecuencia, tal vez deberíamos analizar cualitativamente las Sentencias dictadas en este período. Pero ese propósito excede el nuestro en el presente trabajo, aunque ya hemos realizado alguna observación sobre una crítica que en este ámbito se viene dirigiendo a la actuación del Tribunal ${ }^{72}$. Nosotros nos centramos en dilucidar si la reforma de 2007 ha conseguido su propósito principal, que era acabar con la congestión del Tribunal.

7. De las estadísticas no se desprenden relaciones de causalidad. De modo que no nos resulta posible afirmar con toda rotundidad que la disminución de asuntos de amparo pendientes ante el Alto Tribunal se deba a la reforma de 2007 o a la aplicación de la misma. En efecto, el descenso del número de asuntos pendientes podría considerarse consecuencia, al menos parcial, de otros factores. En este sentido, puede constatarse en el cuadro número 1 que el número de recursos de amparo interpuestos ha disminuido considerablemente a lo largo de estos diez años: en 2006 se interpusieron 11471, mientras que en 2016 se registraron 6685. Pero en nuestra opinión, más que atribuir a ese descenso de asuntos ingresados el de asuntos pendientes, consideramos que la propia disminución de asuntos registrados resulta atribuible, al menos entre otros factores, a la introducción como requisito de la «especial trascendencia constitucional».

\section{DECEPCIÓN DE LOS JUSTICIABLES}

1. A nuestro juicio, la decepción que está motivando la reforma y el recurso de amparo entre los justiciables no está justificada, si tenemos en cuenta los motivos de inadmisión más frecuentes.

Vamos a explicar que, a la luz de los datos que proporciona la Memoria del Tribunal Constitucional de 2016, no se puede decir que los derechos fundamentales queden desprotegidos por la dureza de la LOTC, sino sobre todo, por el defectuoso planteamiento de los recursos de amparo.

72 Concretamente, se le ha reprochado, como hemos dicho anteriormente, que admite asuntos por considerar que es necesario aclarar doctrina y luego, en la correspondiente Sentencia, no lleva a cabo ninguna aclaración doctrinal. 
Cuadro 4. Motivos de inadmisión de los recursos de amparo según la memoria de 2016

B) MOTIVOS DE INADMISIÓN DE LOS RECURSOS DE AMPARO

\begin{tabular}{lcc}
\multicolumn{1}{c}{ Motivos de inadmisión } & Recursos & Porcentaje \\
\hline $\begin{array}{l}\text { Falta de justificación de la especial trascenden- } \\
\text { cia constitucional }\end{array}$ & 677 & 16,00 \\
$\begin{array}{l}\text { Insuficiente justificación de la especial trascen- } \\
\text { dencia constitucional }\end{array}$ & 1.656 & 39,15 \\
Falta de especial trascendencia constitucional & 662 & 15,65 \\
$\begin{array}{l}\text { Inexistencia de vulneración del derecho funda- } \\
\text { mental invocado }\end{array}$ & 169 & 4,00 \\
$\begin{array}{l}\text { Falta de denuncia de la vulneración del } \\
\text { derecho fundamental }\end{array}$ & 19 & 0,45 \\
Falta de agotamiento de la vía judicial previa & 397 & 9,39 \\
Extemporaneidad del recurso & 179 & 4,23 \\
Falta de subsanación de defectos procesales & 340 & 8,04 \\
Varios motivos & 107 & 2,53 \\
Otros motivos & 24 & 0,57 \\
\hline Total & $\mathbf{4 . 2 3 0}$ & $\mathbf{1 0 0}$ \\
\hline
\end{tabular}

Hay que destacar, comentando el cuadro número 4, que casi diez años después de la reforma de 2007, la inmensa mayoría de las providencias de inadmisión de recursos de amparo se fundamentan en motivos que podemos reconducir a la categoría de defectuosa presentación de la demanda. En efecto, si sumamos el porcentaje de recursos en que hay falta de justificación de la «especial trascendencia constitucional» $(16 \%)$ o insuficiente justificación de la «especial trascendencia constitucional» (39\%), resulta que el $55 \%$ de los recursos de amparo no han sido presentados con un desarrollo aceptable de la «especial trascendencia constitucional». A este porcentaje resulta razonable sumar, para calcular los recursos defectuosamente planteados, aquellos que no denuncian vulneración de derecho fundamental $(0,5 \%)$, los que se presentaron sin agotar correctamente la vía judicial previa (9\%), los extemporáneos (4\%) y los que presentan defectos procesales subsanables que sin embargo el recurrente no subsana 
(8\%), es decir, un $21 \%$ más. Lo que significa que el $76 \%$ de los recursos de amparo que se inadmiten fueron inadmitidos por haber sido presentados de manera defectuosa. Mientras que el Tribunal Constitucional solo inadmitió por no concurrir «especial trascendencia constitucional» el 15,6\% de los recursos presentados y por no existir vulneración de derecho fundamental el $4 \%$.

Los datos relativos a las inadmisiones correspondientes a la defectuosa justificación de la especial trascendencia constitucional o a la carencia de la misma indican que los justiciables no han asumido el sentido de la reforma de 2007, que es no ceñir el recurso de amparo a la exclusiva tutela del ius litigatoris — que queda atribuida a la jurisdicción ordinaria-, sino ordenarlo a la protección de un interés que trasciende el anterior, cual es la tutela de los derechos fundamentales en el plano de la seguridad jurídico-constitucional por medio de la protección de la integridad y pureza de su interpretación uniforme. Los justiciables y sus representantes legales parecen no aceptar plenamente el insoslayable cambio producido en 2007. Las cifras de inadmisión de recursos de amparo por inexistencia, defectuosa justificación o falta de justificación de la especial trascendencia constitucional inducen a pensar que un elevado número de recursos de amparo nunca debió presentarse en el Registro del Tribunal.

2. Ahora bien, se comprende que no resulta fácil, ni de explicar ni de aceptar, desde el punto de vista del Estado de Derecho, que la Ley y el legislador reconozcan que pueden quedar sin remedio algunas vulneraciones de derechos fundamentales, a pesar de que lleguen a conocimiento del supremo garante de estos últimos.

No obstante, la idea de establecer requisitos similares a la especial trascendencia constitucional se está implantando en la jurisdicción ordinaria. La defensa de este planteamiento desde el punto de vista teórico, es que de esta manera el Tribunal Supremo llega a conocer de más asuntos pues ahora los asuntos se seleccionan por el interés casacional objetivo y no en razón de la cuantía. Es decir, se argumenta que en la actualidad el Tribunal Supremo podrá dictar sentencias de casación sobre asuntos que, por razón de la cuantía, no habrían conseguido alcanzar el conocimiento del Tribunal Supremo.

Pero este planteamiento no resulta convincente. Entre los operadores jurídicos está muy generalizada la opinión de que un tribunal inferior, si no teme de alguna manera que un tribunal superior revoque o anule una decisión suya, no se preocupará de cumplir la doctrina sentada por el tribunal superior. Por tanto, la idea de que como el Tribunal Constitucional ya ha fijado la doctrina sobre los derechos fundamentales en los años transcurridos desde 1980 en que comenzó a funcionar, hasta 2007, y ahora hay que dejar en manos de la jurisdicción ordinaria la aplicación de su doctrina, es ilusoria. Y de la misma manera, los tribunales inferiores, si empiezan a ver cómo el Tribunal Supremo solamente dicta sentencias en casos que supongan alguna innovación jurisprudencial, lo que hará será despreocuparse de la doctrina del Tribunal Supremo. En definitiva, el sistema de recursos no tiene solamente la finalidad obvia de enmendar la actuación errónea de los órganos judiciales una vez que la 
misma se ha producido, sino también la muy importante de prevenir que esas defectuosas actuaciones se produzcan, de constreñir a los órganos judiciales a administrar justicia correctamente.

Por ello, los operadores jurídicos, o la menos muchos de ellos, consideran que, en la práctica, tanto la doctrina del Tribunal Constitucional como la del Tribunal Supremo se aplicará cada vez menos y el recurrente o justiciable no tendrá manera alguna de luchar contra esta situación.

Pero esta es la orientación actual del legislador con referencia a los altos tribunales. Así, con referencia al Tribunal Supremo se ha introducido un requisito, el llamado «interés objetivo casacional», en el recurso de casación, con la pretensión de que de esta manera se forme jurisprudencia sobre un abanico de temas más amplio, no condicionado por la cuantía del asunto. El requisito del interés casacional se ha introducido tanto en el ámbito civil ${ }^{73}$ (art. 477 de la Ley de Enjuiciamiento Civil) como en el contencioso administrativo (art. 88 de la Ley de Jurisdicción Contencioso Administrativa) o en el penal (art. 889 de la Ley de Enjuiciamiento Criminal). Es una solución muy discutible, pero desde el punto de vista del legislador no se comprende el porqué de la existencia de tantas instancias.

3. El Tribunal Constitucional se ha esforzado en que el incidente de nulidad de actuaciones sea efectivo como compensación de la disminución de garantías que supuso la introducción del requisito de la especial trascendencia constitucional en la reforma de la LOTC de 2007.

El Alto Tribunal se ha mostrado algo vacilante respecto de la finalidad del incidente de nulidad de actuaciones y en relación con la posibilidad de que pueda atribuirse a la providencia que inadmite un incidente de nulidad de actuaciones una lesión autónoma, de modo que su doctrina ha ido evolucionando desde la declaración de la falta de autonomía lesiva de la providencia de inadmisión del incidente a pronunciamientos en los que se le reconoce dicha autonomía, y por tanto, la posibilidad de reconocer la vulneración del derecho fundamental a la obtención de una respuesta motivada por parte de la providencia que inadmite el incidente de nulidad de actuaciones. Veámoslo.

En la STC 114/2009, de 14 de mayo, FJ 4, se mantenía la doctrina tradicional sobre la motivación, de raigambre práctica y utilitaria, que llevaría a considerar que la lesión procedente de la providencia inadmitiendo el incidente de nulidad carecería

73 V. GonZÁlez García, J. M., «Consideraciones sobre el recurso de casación civil español y su valor como instrumento al servicio de la interpretación uniforme del derecho», en Derecho Procesal Contemporáneo (Coord. Raúl Tavolari Oliveros), Ponencias de las XXII Jornadas Iberoamericanas de Derecho Procesal Facultad de Derecho de la Universidad de Chile, Thompson Reuters, 2010, pp. 1244-1262, y «Recurso de casación civil e interpretación uniforme del derecho: algunos instrumentos de derecho comparado y de derecho interno para la interpretación uniforme del derecho, (del avis al amicus curiae)», en El recurso de casación civil (José Bonet navarro dir.; José Martín Pastor, coord.), Cizur Menor (Navarra), Aranzadi Thompson Reuters, 2010, pp. 259-269. 
de relevancia constitucional en cuanto que del otorgamiento del amparo no resultaría ningún efecto útil. También podrían traerse a colación en el sentido que venimos apuntando los AATC 124/2010, de 4 de octubre, 19/2011, de 28 de febrero, FJ 2 y STC 187/2012, de 29 de octubre.

Ahora bien, parece que la necesidad de que la reforma del recurso de amparo operara con verdadera eficacia y que sus fines fueran satisfechos, impulsó un cambio de la doctrina tradicional en relación con la existencia de vulneración del derecho fundamental por la ausencia de motivación de la providencia que inadmitía el incidente de nulidad de actuaciones. El Tribunal Constitucional en otras Sentencias se replantea la cuestión relativa a la relevancia constitucional en cuanto a la utilidad del otorgamiento del amparo, haciendo pedagogía de la naturaleza y fines del incidente.

En efecto, el giro jurisprudencial parece que se inició con la STC 107/2011, de 20 de junio, FJ 5, que por primera vez profundizaba sobre el incidente de nulidad de actuaciones, y amagaba el referido cambio respecto de la tradicional y uniforme jurisprudencia.

Tras dicho pronunciamiento, no encontramos —aproximadamente en tres años-, ningún otro que atribuya carácter autónomo a la vulneración que se atribuye al incidente de nulidad de actuaciones. Pero la STC 9/2014, de 27 de enero, FFJJ 4 y 5, que confirmaría la STC 101/2015, de 25 de mayo, vuelve a proclamar el carácter autónomo de la vulneración del derecho a la obtención de una resolución motivada atribuida a una providencia de inadmisión del incidente de nulidad de actuaciones.

4. No obstante, hasta donde hemos alcanzado a ver, la opinión mayoritaria es que el incidente de nulidad de actuaciones como compensación a la pérdida de garantías que supone la introducción del requisito de la especial trascendencia constitucional para el recurso de amparo es insuficiente.

Está muy generalizada la opinión de que la ampliación del incidente de nulidad de actuaciones no fue una buena solución. Se ha señalado que genera un volumen de incidentes excesivo para el fin que se pretende lograr. Que entrega el control de los actos judiciales al propio controlado. Que pretende un desdoblamiento imposible del órgano judicial, obligado a operar, cuando dicta la resolución que va a dar lugar al incidente de nulidad de actuaciones, con todo el ordenamiento jurídico como criterio, mientras que, pocas semanas después, tendrá que entender del mismo asunto utilizando como criterio solamente los derechos fundamentales. Que la ampliación material a los derechos sustantivos es improcedente ${ }^{74}$ porque es imposible que un derecho

${ }^{74}$ En sentido crítico acerca de la ampliación del incidente de nulidad de actuaciones, v. AguiLERA Morales, M., «El incidente de nulidad de actuaciones ex art. 241 LOPJ: una mala solución para un gran problema», en Revista General de Derecho Procesal, Iustel, n. ${ }^{\circ} 31$, Septiembre 2013; y BELADÍEZ Rojo, M., «La función constitucional del incidente de nulidad de actuaciones del art. 241 LOPJ», en Arroyo Jiménez, L., Beladíez Rojo, M., Ortega Carballo, C., Rodríguez de Santiago, J.M., (coord.), El juez del derecho administrativo. Libro bomenaje a Javier Delgado Barrio, Marcial Pons, Ediciones Jurídicas y Sociales, Madrid, 2015. 
fundamental sustantivo pueda ser alegado por primera vez en el incidente de nulidad de actuaciones, salvo casos muy excepcionales que ya se contemplaban en la versión anterior del art. $241 \mathrm{LOPJ}^{75}$.

\section{POSIBLES MEJORAS}

1. Pensamos que la disminución de garantías que supuso la introducción de la «especial trascendencia constitucional», que no ha alcanzado a compensar la ampliación del incidente de nulidad de actuaciones, hace conveniente un cambio legislativo que disminuya el abanico de resoluciones recurribles en amparo ante el Tribunal Constitucional, reducirlas a determinadas resoluciones de los Tribunales Superiores de Justicia y del Tribunal Supremo ${ }^{76}$, Tribunales en los que deberían crearse Salas especializadas en derechos fundamentales. Las resoluciones de otros órganos serían recurribles ante estas Salas (las de los Tribunales Superiores de Justicia, cuando no fueran recurribles ante el Tribunal Supremo).

No parece necesario un procedimiento de protección de los derechos de varias instancias, con órganos judiciales especializados. Cabe mantener los diferentes procedimientos existentes en los diferentes órdenes jurisdiccionales ${ }^{77}$, pero descargando

75 V. TenORIO SÁnCHeZ, P., El Recurso de Amparo ante el Tribunal Constitucional. Perspectivas de reforma. Wolters Kluwer, 1. ${ }^{a}$ edición, octubre de 2014, páginas 307 y siguientes y bibliografía allí citada.

76 Esto lo propuso, como hemos visto, PÉrez Tremps, P., en su artículo «Tribunal Constitucional, juez ordinario y una deuda pendiente del legislador», en AAVV, La reforma del recurso de amparo, Valencia, 2004, pp. 211 a 214. Aunque no es este el objeto directo de su trabajo, parece de análogo criterio Cabañas, quien lamenta que en lugar de la ampliación del incidente de nulidad de actuaciones no se haya procedido a un reforzamiento generalizado de los procedimientos de amparo judicial ordinario de los derechos fundamentales junto con medidas orgánicas tendentes a ese mismo fin, tanto en primera o única instancia judicial, donde están ausentes las características de preferencia y sumariedad, como también en sede recurso. CABAÑAs GARCía, J. C., «El recurso de amparo que queremos (Reflexiones a propósito de la Ley Orgánica 6/2007, de 24 mayo, de reforma parcial de la Ley Orgánica del Tribunal Constitucional)», en REDC, número 88, enero-abril (2010), pp. 51 y 52. También García Couso, S., en «El nuevo modelo de protección de los derechos fundamentales tras la aprobación de la LO 6/2007: la objetivación del amparo constitucional y la tutela subjetiva de los Derechos por la jurisdicción ordinaria y el Tribunal Europeo de Derechos Humanos», Revista Europea de derechos fundamentales, núm. 15, 1 semestre 2010, p. 158: Tras dudar de la eficacia de la ampliación de la nulidad de actuaciones, dice que «Quizás hubiera sido más conveniente potenciar la labor de los Tribunales Superiores de Justicia y del Tribunal Supremo en la labor de protección de los Derechos y libertades fundamentales, y crear una sala especial en ellos que se encargara del conocimiento de dichas cuestiones».

77 Sin perjuicio de considerar la preferencia en el despacho de las causas y la rapidez y cortedad de los plazos como característica constitucional necesaria del amparo judicial. Sobre este último aspecto, Cabañas García, J. C., «La tutela jurisdiccional de los derechos fundamentales en el orden social», Documentación Laboral, número 42, Madrid, 1994, pp. 76 a 79; del mismo autor, «El recurso de amparo que queremos (Reflexiones a propósito de la Ley Orgánica 6/2007, de 24 mayo, de reforma parcial de la Ley Orgánica del Tribunal Constitucional)», en Revista Española de Derecho Constitucional, número 88, enero-abril (2010), pp. 44 y 45; DíEZ-PICAZo GiménEZ, I., Tribunal constitucional, jurisdicción ordinaria y derechos fundamentales, (coautor, con Andrés de la Oliva), Madrid, 1996, pp. 97 a 101. 
peso del Tribunal Constitucional en el Tribunal Supremo, en el que debería crearse una Sala de amparo constitucional, y en los Tribunales Superiores de Justicia. Esta Sala de amparo en el Tribunal Supremo cumpliría el objetivo perseguido con la ampliación del incidente de nulidad de actuaciones que se llevó a cabo en la reforma de 2007, es decir, entendería de las quejas que denunciaran una vulneración de derechos fundamentales realizada por un órgano judicial en una resolución contra la que no cupiera otro recurso.

¿Por qué excluimos la supresión de los procedimientos sectoriales existentes? Consideramos que, al introducir cambios, debe tenerse en cuenta la evolución de las instituciones. En particular, en el caso que nos ocupa, el ensanchamiento de la concepción de nuestra justicia constitucional, merced a la amplia interpretación de la fuerza normativa de la Constitución. Al ser aplicables los derechos fundamentales en todo tipo de procesos, pierde sentido el amparo judicial preferente y sumario por medio de una ley específica de protección de los derechos fundamentales y se pasa a configurar un procedimiento preferente y sumario en cada una de las ramas judiciales o sectores materiales del ordenamiento.

2. Por otra parte, para mejorar la protección de los derechos fundamentales por la jurisdicción ordinaria se debería realizar una interpretación literal del requisito de la invocación del derecho fundamental ${ }^{78}$, tan pronto como el mismo es vulnerado. $\mathrm{O}$ cabría reforzar incluso el tenor literal de la ley para endurecer este requisito, si bien esto último no parece indispensable.

Un mayor rigor en la exigencia de la invocación del derecho fundamental vulnerado $^{79}$ por parte del recurrente tiene la ventaja de obligar al juez a una mayor exacti-

${ }^{78}$ Como se sabe, la LOTC exige que se denuncie la vulneración del derecho fundamental tan pronto como se tenga conocimiento de la misma. Y además exige que se invoque el derecho fundamental vulnerado. Esto es lógico y coherente con el carácter vinculante de los derechos fundamentales en todos los procesos y con el carácter subsidiario del recurso de amparo ante el Tribunal Constitucional. Concretamente, la LOTC dice que «Las violaciones de los Derechos y libertades susceptibles de amparo constitucional, que tuvieran su origen inmediato y directo en un acto u omisión de un órgano judicial, podrán dar lugar a este recurso siempre que se cumpla...», entre otros requisitos, "Que se haya denunciado formalmente en el proceso, si hubo oportunidad, la vulneración del derecho constitucional tan pronto como, una vez conocida, hubiera lugar para ello» [art. 44.1 c) LOTC]. La referida Ley no incluye este requisito al regular el amparo contra actos y disposiciones de los órganos ejecutivos (art. 43 LOTC).

79 En el ámbito doctrinal, algunos autores han llamado la atención sobre la forma en que debe entenderse cumplido el requisito de la invocación. En este sentido, Borrajo InIESTA, I. Diez-PICAZO Giménez, I. Fernández FArreres, G. El derecho a la tutela judicial efectiva y el recurso de amparo. Una reflexión sobre la jurisprudencia constitucional, Madrid, Civitas, 1995, pp. 162 y 163 indican que para estimar cumplido el requisito de la invocación es preciso que el recurrente haya procedido a calificar jurídicamente la lesión producida, calificación sin la cual no debe darse viabilidad procesal a la demanda de amparo. El recurrente tiene la carga de plantear ante el órgano judicial el contenido constitucional de la infracción que denuncia, porque solo de esa forma da posibilidad al órgano judicial de apreciar la verdadera dimensión constitucional de la infracción. (Aunque los autores se refieren, en concreto, al 
tud desde el punto de vista de las exigencias de congruencia y motivación propias de la sentencia.

La interpretación espiritualista ${ }^{80}$ del requisito de la invocación del derecho fundamental tan pronto como sea vulnerado ha podido tener a la larga una influencia negativa en la protección de los derechos fundamentales por parte de la jurisdicción ordinaria. Dicho de otra manera, si los abogados supieran que, solo si tan pronto como se vulnera un derecho fundamental se plantea el problema como tal (invocando el precepto constitucional concreto y el derecho constitucional vulnerado y argumentando la demanda o escrito desde la perspectiva de los derechos fundamentales y en su caso invocando la jurisprudencia que los ha desarrollado) los derechos fundamentales serían mucho más conocidos y aplicados por los abogados y por la jurisdicción ordinaria. Es más, cabe imaginar que el desarrollo de la jurisprudencia de los derechos fundamentales fuera tal que apareciera la especialidad profesional de abogado constitucionalista, que debería ser consultado con motivo de cualquier pleito, desde el comienzo del mismo, siempre que la persona que lo emprendiera (o su representante legal) tuviera en mente la posibilidad de agotar sus posibilidades de defensa llegando al Tribunal Constitucional. Como se sabe, si la cuestión no se plantea correctamente desde el principio, es muy difícil que prospere.

Cuando se adoptó la concepción espiritualista del requisito de la invocación, resultaba coherente dar acceso al Tribunal Constitucional por vía de recurso de amparo a aquellos supuestos en los que el justiciable no hubiera planteado su problema en términos de derechos fundamentales ante la jurisdicción ordinaria. Parecía que concediendo al supremo garante de los derechos la posibilidad de contemplar desde la perspectiva de los derechos fundamentales cualquier problema jurídico planteado ante cualquier jurisdicción, se enviaba el mensaje a los jueces y tribunales de que, para estar seguros de que estaban resolviendo la cuestión que se les planteaba no sólo desde la perspectiva de la legalidad ordinaria, sino también desde la perspectiva de los derechos fundamentales, había que proceder a la admisión de asuntos en los que las propias partes no hubieran planteado el problema desde aquella perspectiva ante los propios jueces y tribunales.

\footnotetext{
derecho a la tutela judicial efectiva y sus diferentes vertientes). Añaden estos autores que nuestro Tribunal Constitucional aplica desigualmente el requisito de la invocación previa, lo cual es particularmente claro en el caso del derecho a la imparcialidad del juez, que desde la STC 145/1988 se encuadra en el ámbito del derecho al proceso con todas las garantías del art. 24.2 CE; esa desigual aplicación, puede apreciarse en la exigencia de la invocación previa mediante la oportuna recusación, cuando se trata de causa objetiva y no ha mediado notificación alguna de la composición de la sala y de asignación de magistrado ponente, ya que, de acuerdo con una línea jurisprudencial, la falta de notificación no impide a la parte instar esa notificación o formular protesta, mientras que según otra postura jurisprudencial, la ausencia de notificación le impide invocar y, en consecuencia, provocar el restablecimiento por los propios tribunales ordinarios de la supuesta vulneración del derecho fundamental.

${ }^{80}$ El Tribunal Constitucional ha espiritualizado este requisito hasta hacerlo casi desaparecer. No es preciso mencionar el derecho, ni el precepto, tan sólo plantear el problema. Esta doctrina ya aparece en STC 95/1983, de 14 de noviembre.
} 
En la actualidad, como el Tribunal Constitucional admite que la invocación del derecho fundamental se ha producido siempre que el problema de fondo se haya planteado ante el órgano judicial (sin necesidad de invocar el precepto de la Constitución vulnerado ni reconducir los hechos a un derecho fundamental determinado, ni argumentar desde la perspectiva de los derechos fundamentales), resulta que los abogados casi pueden plantearse por primera vez si acuden al Tribunal Constitucional una vez que han perdido el pleito en la última instancia que les ofrece la vía judicial ordinaria.

Se dirá que esto no sucede con relación a todos los derechos. Así, si se vulnera la libertad de expresión, el pleito, desde el principio, versará sobre la libertad de expresión. Y es verdad, pero ocurre en muchos casos, en concreto en las siguientes hipótesis: 1) Cuando se descubre después de la Sentencia del Tribunal Supremo o de la última instancia del poder judicial que se podía haber enfocado el asunto desde la perspectiva de otro derecho fundamental. 2) Cuando se trata del derecho a la tutela judicial efectiva y en particular de la razonabilidad de la interpretación de la legislación ordinaria. Debemos tener en cuenta que este es el derecho más invocado ante el Tribunal Constitucional.

A partir de la reforma de 2007, un asunto puede no debatirse frontalmente desde la perspectiva de los derechos fundamentales como consecuencia de lo siguiente: 1) sólo es preciso, en principio, plantear el problema, no su enfoque desde los derechos fundamentales; 2) cuando se hace esto último, el Tribunal Supremo o último tribunal de instancia puede decir que se debía de haber planteado antes. 3) ante el Tribunal Constitucional sólo se debatirá si el asunto tiene, además, «especial trascendencia constitucional».

Si el Tribunal Constitucional no interpretara de manera espiritualista el requisito de la invocación, cabe pensar que podría haber un período de tiempo en el que algunos justiciables se verían disminuidos en sus posibilidades de acceso ante el Tribunal Constitucional, pero a medio y a largo plazo el desarrollo de los derechos fundamentales y su aplicación por la jurisdicción ordinaria serían más amplios, profundos y rigurosos. Se profundizaría en concepción del Estado no ya sólo como un simple Estado de Derecho, sino como un Estado de derechos fundamentales y se extendería la misma.

Quizás, para no irrogar perjuicios en la transición de un sistema a otro a los justiciables, sería conveniente una reforma legislativa que mostrara la voluntad inequívoca del legislador de que el Tribunal no continúe con su aplicación espiritualista de la exigencia legal de la invocación. Bastaría con añadir por ejemplo la expresión «en todo caso» en el subapartado «c» del artículo 44.1 LOTC o aludir a que la invocación del derecho fundamental debe realizarse explícitamente con indicación del precepto constitucional vulnerado, del derecho fundamental violado y con argumentación sobre el asunto desde la perspectiva de los derechos fundamentales.

Pero la exigencia de rigor y precisión en la invocación del derecho fundamental no exige un cambio legislativo, lo que la hace fácilmente viable. 
3. Hemos visto que una mayoría abrumadora de los recursos de amparo ante el Tribunal Constitucional son inadmitidos porque se plantean defectuosamente. Esto se debe al desconocimiento por parte de muchos operadores jurídicos de los derechos fundamentales y en particular de la doctrina del Tribunal Constitucional y a la escasez de especialistas en esta materia. Ciertamente, los abogados saben que pueden invocar los derechos fundamentales en todo tipo de procesos y de hecho los invocan. Pero muchas veces se trata de una invocación superficial y genérica. Ante este tipo de invocaciones, existe el riesgo de que el órgano judicial, sabedor de que en la actualidad no solo es necesario que se haya vulnerado un derecho fundamental, sino además, que el asunto tenga especial trascendencia constitucional, no sienta necesidad de profundizar en el conocimiento y aplicación de la jurisprudencia del Tribunal Constitucional.

Por estas razones, es aconsejable, al menos como buena práctica, que los abogados presenten el embrión del posible recurso de amparo ante la jurisdicción ordinaria, incluyendo la justificación de la especial trascendencia constitucional, aunque esto último no es indispensable.

Title:

What has happen with amparo appeal before the Constitutional Court?

\section{Summary:}

1. Introduction; 2. First period in the interpretation of the reform of 2007: from the promulgation of the law to the echr arribas antón; 3. Second period in the application of the reform of 2007: from the echr arribas antón to the present time; 4 . Balance of the application of the reform of 2007 ten years after its promulgation; 5. Deception of the justiciables; 6. Possible improvements.

\section{Resumen:}

El trabajo estudia la evolución y situación actual del recurso de amparo ante el Tribunal Constitucional. Parte de la base de que la cuestión consiste en analizar la aplicación y resultados de la reforma de la Ley Orgánica del Tribunal Constitucional que se realizó en 2007. La reforma se aplicó con algún titubeo inicialmente por parte del Tribunal Constitucional pero finalmente se ha llevado hasta las últimas consecuencias. Esto ha producido un resultado positivo, pues el Tribunal Constitucional está prácticamente al día, muy lejos de la situación de inviabilidad que se di- 
bujaba cuando se concibió la reforma, es decir, en torno al año 2006. Pero la reforma sigue siendo criticada por haber disminuido las garantías del justiciable. Sin embargo, los datos que ofrece en sus Memorias el Tribunal Constitucional permiten constatar que la inmensa mayoría de los recursos se inadmiten por defectuoso planteamiento. El trabajo propone como mejoras el establecimiento de salas de amparo en los Tribunales Superiores de Justicia y en el Tribunal Supremo y el rigor en la exigencia de la invocación del derecho fundamental tan pronto como es vulnerado. Además, considera aconsejable que los abogados no se limiten a la invocación genérica del derecho fundamental, sino que expongan ante la jurisdicción ordinaria el embrión del posible recurso de amparo.

\begin{abstract}
:
The article studies the evolution and the current situation of the amparo appeal before the Constitutional Court. The question is to analyze the application and results of the reform of the Constitutional Court Organization Act that was held in 2007. The reform was applied with some hesitation initially by the Constitutional Court but finally has been carried to the last consequences. This has produced a positive result, because the Constitutional Court is practically up to date, very far from the situation of unfeasibility that was drawn when the reform was conceived, that is to say, around the year 2006. But the reform continues being criticized for having diminished the guarantees of the defendant. However, the data that the Constitutional Court offers in its reports allow us to confirm that the vast majority of the appeals are inadmissible due to a defective approach. The work proposes as improvements the establishment of amparo chambers in the Superior Courts of Justice and in the Supreme Court and the rigor in demanding the invocation of the fundamental right as soon as it is violated. In addition, it considers advisable that the lawyers expose before the ordinary jurisdiction the embryo of the possible resource of amparo.
\end{abstract}

\title{
Palabras clave:
}

Recurso de amparo; Especial trascendencia constitucional; Incidente de nulidad de actuaciones; Garantías constitucionales; Salas de amparo; Ley Orgánica del Tribunal Constitucional; Invocación del derecho fundamental; TEDH; Tribunal Supremo; Tribunales Superiores de Justicia.

\section{Key words:}

Amparo Appeal. Special constitutional significance; Motion for dismissal of proceedings; Constitutional guarantees Amparo Chambers; Constitutional Court Organization Act; Invoking the fundamental right; ECHR; Supreme Court; Superior Courts of Justice. 